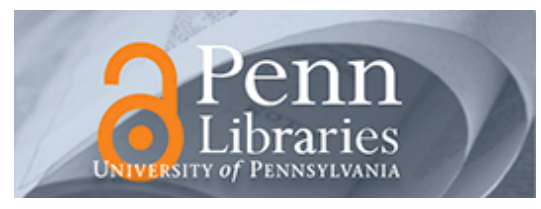

University of Pennsylvania ScholarlyCommons

\title{
Price Discrimination and Bargaining: Empirical Evidence From Medical Devices
}

Grennan. Matthew

University of Pennsylvania

Follow this and additional works at: https://repository.upenn.edu/hcmg_papers

Part of the Health Services Research Commons, Other Medicine and Health Sciences Commons, and the Other Public Health Commons

\section{Recommended Citation}

Matthew, G. (2013). Price Discrimination and Bargaining: Empirical Evidence From Medical Devices. American Economic Review, 103 (1), 145-177. http://dx.doi.org/10.1257/aer.103.1.145

This paper is posted at ScholarlyCommons. https://repository.upenn.edu/hcmg_papers/70

For more information, please contact repository@pobox.upenn.edu. 


\title{
Price Discrimination and Bargaining: Empirical Evidence From Medical Devices
}

\author{
Abstract \\ Many important issues in business-to-business markets involve price discrimination and negotiated \\ prices, situations where theoretical predictions are ambiguous. This paper uses new panel data on buyer- \\ supplier transfers and a structural model to empirically analyze bargaining and price discrimination in a \\ medical device market. While many phenomena that restrict different prices to different buyers are \\ suggested as ways to decrease hospital costs (e.g., mergers, group purchasing organizations, and \\ transparency), I find that: (i) more uniform pricing works against hospitals by softening competition; and \\ (ii) results depend ultimately on a previously unexplored bargaining effect. \\ Disciplines \\ Health Services Research | Other Medicine and Health Sciences | Other Public Health
}




\title{
Price Discrimination and Bargaining: Empirical Evidence from Medical Devices
}

\author{
By Matthew GRennan*
}

\begin{abstract}
Many important issues in business-to-business markets involve price discrimination and negotiated prices, situations where theoretical predictions are ambiguous. This paper uses new panel data on buyersupplier transfers and a structural model to empirically analyze bargaining and price discrimination in a medical device market. While many phenomena that restrict different prices to different buyers are suggested as ways to decrease hospital costs (e.g., mergers, group purchasing organizations, and transparency), I find that: ( $i)$ more uniform pricing works against hospitals by softening competition; and (ii) results depend ultimately on a previously unexplored bargaining effect. (JEL C78, L13, L14, L64)
\end{abstract}

In business-to-business markets, prices are often negotiated. This can result in different buyers paying substantially different prices for the same product from the same supplier. Whenever some buyers are able to "get a better deal" than others in this way, policymakers, potential middlemen, and other buyers naturally wonder if interventions that move toward more uniform prices might make buyers better off. This paper estimates the welfare effects of different hospitals paying different prices - and several interventions that would make prices more uniform-in the market for coronary stents, a "blockbuster" medical device on which hospitals spend over $\$ 5$ billion each year.

The price of medical technologies, such as coronary stents, is often cited as a driver of the increasing costs of healthcare (Keehan et al. 2011). Many of the interventions intended to lower these costs impose restrictions that would make prices more uniform, but the actual effects of these interventions on prices and welfare are

\footnotetext{
* Rotman School of Management, University of Toronto, 105 St. George Street, Toronto, ON, M5S 2L4, Canada (e-mail: matthew.grennan@rotman.utoronto.ca). Data for this research was provided by Millennium Research Group (www.mrg.net). This paper further develops ideas from my NYU Stern PhD thesis. Special thanks for the guidance and encouragement throughout this research project go to my dissertation committee: John Asker, Adam Brandenburger, Allan Collard-Wexler, Michael Katz, and Bernie Yeung. I also benefited from discussions with Victor Aguirregabiria, Heski Bar-Isaac, Luís Cabral, Ken Corts, Catherine de Fontenay, J. P. Eggers, Avi Goldfarb, Mara Lederman, Robin Lee, P. T. Leger, Hong Luo, Matt Mitchell, Gabriel Natividad, Ariel Pakes, Rob Salomon, Gus Stuart, Ali Yurukoglu; seminar audiences at Analysis Group, AZ, Columbia, FTC, GA, HEC Montreal, IIOC, LSE, NYU, Northwestern (Kellogg), Rochester (Simon), Toronto (Rotman), and Yale SOM; and two anonymous referees. Andy Cron, John Brumleve, Mark Bly, Rob Tumarkin, and many others have been helpful in teaching me about medical device manufacturing and sales. Physicians and administrators at NYU Medical Center and $\mathrm{CGH}$, Sterling, IL were especially generous with their time and knowledge regarding hospital purchasing and the inner workings of a cardiac catheterization lab. Some industry background research was conducted while attending the Transcatheter Cardiovascular Therapeutics 2008 conference, which was made possible by the Cardiovascular Research Foundation.

${ }^{\dagger}$ To view additional materials, visit the article page at http://dx.doi.org/10.1257/aer.103.1.145.
} 
not well understood. For example, hospital mergers make prices more uniform by creating a single buyer from several. Though a common justification for hospital mergers is to lower input costs, evidence that they do so has been mixed (Dranove and Lindrooth 2003). Group purchasing organizations (GPO)—where a group of buyers delegate purchasing authority to a third party-also make prices more uniform, and they permeate much of hospital purchasing. The actual value provided by GPOs is a constant topic of debate, however, especially in the market for coronary stents and other "physician preference items" (Burns and Lee 2008). The recent healthcare reform efforts in the United States have brought calls for greater market transparency, with many anticipating that such reform would lead to more uniform prices across hospitals, but mixed predictions as to who might benefit (Kyle and Ridley 2007). The lack of consensus regarding the impact of these interventions on the cost of critical healthcare inputs is driven in part by the fact that economic theory alone offers ambiguous predictions, and necessary data are difficult to procure.

This paper uses new panel data on the prices and quantities transferred between hospitals and coronary stent manufacturers to estimate a structural model of supply and demand that incorporates bargaining over prices. I then use the estimated model to compare welfare outcomes under the current pricing regime (where different hospitals pay different prices for the same stent) and counterfactual regimes with transparency, group purchasing, and mergers. I find that: (i) in this market, more uniform pricing actually works against hospitals through a competition softening effect; and (ii) results depend ultimately on a previously unexplored bargaining effect. Whether a given intervention will raise or lower stent prices hinges on the details of how it unlocks these two forces.

The way in which a change to more uniform pricing affects competition relates directly to the theory of price discrimination with oligopoly. ${ }^{1}$ If hospitals are more vertically differentiated from one another in their preferences for stents (what the literature would call best-response symmetry among manufacturers), then competition will tend to intensify with more uniform prices (Holmes 1989). If hospitals are instead more horizontally differentiated (best-response asymmetry), then competition will tend to soften with more uniform pricing, as manufacturers price to their captive markets (Corts 1998). Thus, understanding if different prices are good or bad for hospitals requires knowing first the extent to which variation in price is due to variation in demand, and then whether this demand variation is vertical or horizontal. A complete analysis requires going further and accounting for the fact that prices are not "set" by suppliers as they are in the price discrimination literaturestent prices are negotiated.

When buyers and suppliers negotiate prices, supplier costs, buyer willingnessto-pay, and competition determine only a range of potential prices (versus a single price) for each buyer and supplier. ${ }^{2}$ The final price will depend on what I refer to as each firm's bargaining ability - the ability to reach a more favorable point within that range. Heterogeneity in bargaining abilities turns out to be important in

\footnotetext{
${ }^{1}$ Stole (2007) and Armstrong (2006) offer excellent reviews of this large literature.

${ }^{2}$ The simplest example is bilateral monopoly, where the buyer won't pay a price above its willingness-to-pay, and the seller won't sell for a price less than its cost. With a competing supplier, the buyer has an outside option that lowers the top of this range, but as long as the competing product is not a perfect substitute, there will still be a range of prices at which the buyer and supplier could trade.
} 
explaining the variation in prices for the same stent sold to different hospitals - as one hospital purchasing manager put it, "There is a lot of wiggle room [in prices]." 3 Further, this importance of variation in bargaining ability means that a complete understanding of any market intervention will require understanding how it affects bargaining abilities, in addition to competition. The theoretical model in this paper illustrates precisely how bargaining adds a new dimension to debates on price discrimination and uniform pricing and how this bargaining effect interacts with the previously established competitive effect.

Despite the ambiguity of the predictions from theoretical work on price discrimination and bargaining, the empirical literatures in these areas are still relatively small. This is largely because empirical studies of business-to-business markets (where both often occur) have been limited by the difficulty of accessing data on transfers between buyers and suppliers. Of the recent empirical studies involving price discrimination (Duggan and Scott Morton 2006; Hastings 2008; Villas-Boas 2009), bargaining (Dranove, Satterthwaite, and Sfekas 2008; Dafny 2010; Ho 2009; Crawford and Yurukoglu 2012), and vertical contracting relationships more generally (Ho, Ho, and Mortimer 2012), only Hastings (2008) and Dafny (2010) have had access to data on the actual buyer-supplier transfers. Hastings (2008) looks at the effects of price discrimination versus uniform pricing between gasoline stations and wholesalers, but does not consider bargaining. Dafny (2010) is interested in diagnosing the presence of market power among providers of employee health insurance, but not analyzing bargaining or price discrimination per se. This paper builds on previous empirical and theoretical research by quantifying several mechanisms previously illustrated in theory and demonstrating new interactions between price discrimination and bargaining in a context where both are important.

Central to this study is an unusually detailed panel dataset, providing the quantities purchased and prices paid for all coronary stents sold to 96 US hospitals from January 2004 through June 2007, at the stent-hospital-month level. The stent market is a business-to-business market in which hospitals generate revenue by implanting stents during angioplasty procedures, and the stent is a necessary input that the hospital must purchase from a device manufacturer. Contracts are negotiated, stipulating the price at which the hospital can purchase a given stent over a specified period of time, and different hospitals negotiate different prices for the same stent. This price variation has significant implications for profits. Moving from the twenty-fifth to seventy-fifth percentile in price would result in a change of about $\$ 300,000$ annually (about 4 nurses' salaries) at the average-sized hospital. Section I of the paper provides more details regarding the industry and data.

Even with these detailed data, several important variables-cost, willingnessto-pay, and bargaining ability-are unobserved. Further, separating the impact of demand and competition on the range of potential prices from the impact of bargaining abilities within that range requires an explicit model of how competition and bargaining determine prices. In Sections II and III, I address these challenges with a structural empirical approach, similar to Berry, Levinsohn, and Pakes (1995), but using a pricing model that generalizes the standard Bertrand-Nash price-setting

${ }^{3}$ C. Zander, personal communication, September, 2008. 
model to allow for bargaining over prices. The model has two parts: (i) a model of doctor demand for coronary stents uses the price and quantity data to estimate demand for each stent; and (ii) a model of how prices emerge from competition and bargaining uses the demand estimates and the price and quantity data to estimate costs and relative bargaining abilities.

On the demand side, a random coefficients discrete choice model incorporates heterogeneity in preferences for stents across hospitals, physicians, and patients. The fact that prices are fixed in long-term contracts provides two new sources of identification: First, doctor preferences evolve over time while prices remain fixed; so when prices are renegotiated, the movement is along the demand curve. Second, bargaining ability provides a new supply shifter. The resulting willingness-to-pay estimates closely match external data on procedure profits, and estimates of substitution patterns agree with anecdotal evidence that doctors are slightly price-sensitive, are brand-loyal, and can differ widely in their preferences over the different stents available on the market.

Given the demand estimates, I estimate cost and bargaining ability parameters using a pricing model in which each stent manufacturer and hospital engage in bilateral Nash bargaining, and these bilateral outcomes form a Nash equilibrium with each other. This model relates to the theoretical literature on bargaining with externalities (Horn and Wolinsky 1988), and Crawford and Yurukoglu (2012) use a close variant in an empirical setting. I solve the model for the equilibrium pricing equation, which is useful in two ways: First, it clarifies how this bargaining model is a generalization of the standard Bertrand-Nash differentiated products pricing model, providing a tight link to theoretical work on price discrimination. Second, it shows that price is equal to cost plus a margin that depends on bargaining abilities, elasticities, and the marginal contribution of each product relative to its competitors, making it clear how covariation in price and demand can identify bargaining ability parameters separately from costs. The estimates show that allowing for heterogeneity in bargaining abilities in addition to heterogeneity in demand is critical for explaining the price variation observed in the data. 4

The heterogeneity across hospitals in demand and bargaining abilities also play quantitatively important roles in the counterfactual changes due to transparency, group purchasing, and mergers considered in Section IV. Because different hospitals have doctors with different brand loyalties (variation in hospital demand is more horizontal than vertical), a change to more uniform pricing will soften competition as suppliers price to extract surplus from their captive hospitals. As a result, any intervention that intends to lower prices through making them more uniform must be accompanied by an increase in hospital bargaining ability. I estimate that this required increase can be rather large. In a GPO made of all hospitals in the sample, the bargaining ability of the GPO would have to be above the seventieth percentile of the individual hospital bargaining abilities.

Section IVB extends the analysis to 100 merger simulations in order to inform the conditions under which multi-hospital systems might be able to decrease stent prices. This also generates a deeper understanding of the competitive and bargaining effects

\footnotetext{
${ }^{4}$ A companion paper, Grennan (2012), uses the panel structure of the data and hospital characteristics to further explore the sources of these bargaining abilities.
} 
because the randomly selected hospitals for each merger have varying amounts of symmetry in their preferences. I develop a measure of the extent of (a) symmetry and quantify its relation to merger outcomes. For simulations with postmerger bargaining abilities equal to the mean of the merging hospitals, a one standard deviation increase in symmetry leads to a 1.3 percent increase in hospital surplus. The interaction of this effect with the bargaining effect is also quantitatively significant: the importance of symmetry more than doubles when the postmerger bargaining ability is changed to the maximum of the merging hospitals.

While this paper focuses on the market for coronary stents, price variation across different buyers for the same product - and proposals to restrict it-occur in a variety of markets. Many aspects of the approach used here are flexible enough to be applied to other settings. The credibility of any structural study, however, depends on capturing important industry-specific details, which are the topic of the next section.

\section{Coronary Stents: Industry Description and Data}

The coronary stent industry is not only an example of a business-to-business market, it is also interesting and important in and of itself. The coronary stent is a medical device used in angioplasty, an important treatment for blockages in the arteries surrounding the heart (a condition known as coronary artery disease). These blockages can cause pain, loss of mobility, and eventually heart attack, making coronary artery disease the leading cause of death in the United States. 5 Angioplasty is a minimally invasive technique in which the doctor threads a balloon-tipped catheter from an access point (usually the femoral artery near the groin) to the heart. Using imaging devices, the doctor positions the balloon tip across the blockage, and expands the balloon, compressing the blockage to the artery walls. A stent is a small metal tube that is then placed via catheter where the blockage was cleared and left in the body as structural support for the damaged artery wall. Though angioplasty is attractive due to its minimally invasive nature, traditional stainless steel "bare-metal stents" (BMS) have the drawback that scar tissue growth around this foreign body can lead to significant renarrowing of the artery in about 33 percent of cases. "Drugeluting stents" (DES) attempt to remedy this problem by coating the stent with a drug that discourages scar tissue growth, and they have been successful in reducing the incidence of renarrowing to near 9 percent. ${ }^{6}$

\section{A. The "Economics" of the Stent Market}

With the introduction of DES, stents became the first medical device to reach revenue levels similar to those of a "blockbuster" drug. The three million stents implanted worldwide each year generate annual revenues of more than $\$ 5$ billion to stent manufacturers and $\$ 30$ billion to hospitals and doctors for the stenting procedures.

\footnotetext{
${ }^{5}$ US Department of Health and Human Services, National Institutes of Health, National Heart Lung and Blood Institute Diseases and Conditions Index. www.nhlbi.nih.gov/health/dci/Diseases/Cad/CAD_WhatIs.html (June 2008).

${ }^{6}$ Robert J. Applegate, "Drug-Eluting Stents: The Final Answer to Restenosis?” Wake Forest University Medical Center, http://www1.wfubmc.edu/articles/CME+Drug-eluting+Stents (September 15, 2008).
} 
Hospitals and doctors generate revenue from each angioplasty procedure, usually via reimbursement from a patient's insurer. The reimbursement rates are negotiated by the hospital with each insurer (usually taking Medicare rates, which are not negotiated, as a starting point), so they vary across hospitals and across insurers for each hospital. The average Medicare reimbursement rates for a basic stenting procedure are $\$ 812$ for the doctor, regardless of the type of stent used; and for hospitals, $\$ 10,422$ for a BMS and $\$ 11,814$ for a DES. 7 Reimbursements do not depend on the manufacturer of the stent.

Out of this revenue comes the hospital's costs, including the cost of any stents used. Thus, the hospitals keep in profit any price savings they can achieve on the cost of stents. While in many markets there might be some interaction between the costs negotiated with suppliers and the revenues negotiated from buyers, that is not the case here. For Medicare patients, the reimbursement levels are fixed; and the reimbursements from private insurers are generally negotiated as a markup on Medicare rates across all procedures performed at the hospital. Thus, reimbursement levels at each hospital are fixed with respect to the cost of stents.

\section{B. Data Overview}

The dataset used in this paper is from Millennium Research Group's Marketrack survey of catheter labs, the source that major device manufacturers subscribe to for detailed market research. The goal of the survey is to provide an accurate pic ture of market shares and prices by US region (Northeast, Midwest, South, West)..$^{8}$ The US market is dominated by four large multinational firms: the Abbott Vascular (formerly Guidant) division of Abbott Laboratories, Boston Scientific, Johnson and Johnson's Cordis division, and Medtronic, which together make up over 99 percent of US coronary stent sales. ${ }^{9}$ These manufacturers offered a total of nine BMS and two DES during the sample period.

The key variables in the data are the price paid and quantity used for each stent in each hospital in each month. In addition, the hospitals report monthly totals for different procedures performed, such as diagnostic angiographies, and prices and quantities for other products used in the catheter lab, such as balloon catheters and guiding catheters. After removing hospitals with incomplete reporting (usually failure to report price data-see online Appendix A for details), the dataset I use for analysis is an unbalanced panel of 10,098 stent-hospital-month observations at 96 US hospitals over 42 months from January 2004 through June 2007.10

\footnotetext{
${ }^{7}$ By "basic" I mean single-vessel operations with no "modifiers" for difficulty of the procedure, location of the hospital, etc. These numbers represent the lower bound in revenue for these procedures (Medicare upper bounds are roughly 1.5 times these payments, and private insurers generally reimburse at even higher levels). Numbers from Federal Register, Volume 68, No. 216, November 7, 2003; and Federal Register, Volume 68, Number 148, August $1,2003$.

${ }^{8}$ See www.mrg.net for more details on the survey.

9 iData Research, Inc. "US Markets for Interventional Cardiology" (2006).

${ }^{10}$ According to the American College of Cardiology, this sample represents less than five percent of all cardiac catheterization labs in the United States. The sample, however, is focused on larger labs, and so represents approximately 15 percent of all stenting procedures. Because the dataset used in this paper is sold as market research to the device manufacturers, hospitals are anonymous, which, unfortunately, prevents linking this dataset with other data sources on the hospitals. Of the hospitals in the sample, 31 percent are teaching hospitals and 63 percent are public institutions.
} 
Panel A. Quantities

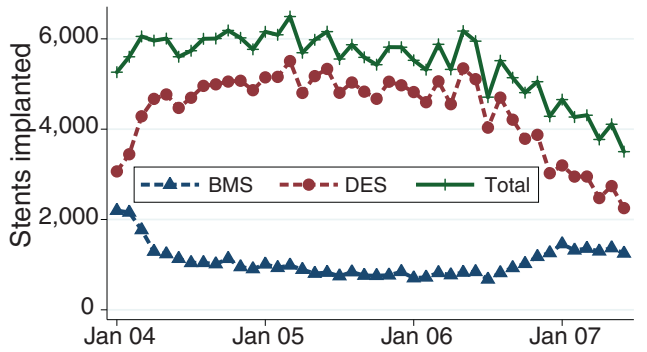

Panel B. Prices

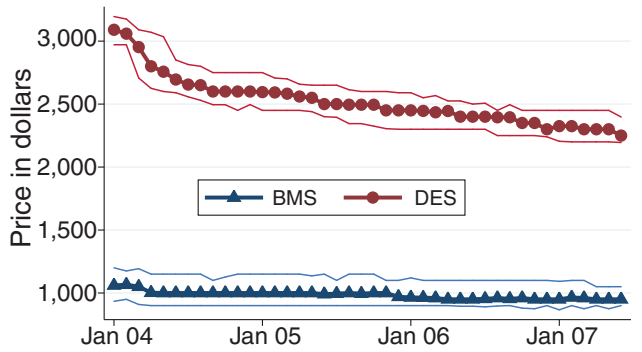

Figure 1. Aggregate Trends in the Market over the SAmple Period

Notes: The quantity graph shows the total number of stents implanted, also broken down into DES and BMS. The price graph shows median prices (and first and third quartiles) of BMS and DES.

TABLE 1 -Price Variation across Hospitals

\begin{tabular}{lcccccc}
\hline \hline Stent & Mean $(\$)$ & SD $(\$)$ & SD/Mean & Min $(\$)$ & Max $(\$)$ & $\mathrm{N}$ \\
\hline BMS4 & 1,006 & 175 & 0.17 & 775 & 1,500 & 25 \\
BMS5 & 926 & 191 & 0.21 & 700 & 1,600 & 23 \\
BMS6 & 952 & 156 & 0.16 & 775 & 1,475 & 26 \\
BMS7 & 1,035 & 174 & 0.17 & 775 & 1,600 & 39 \\
BMS8 & 1,063 & 338 & 0.32 & 800 & 1,950 & 11 \\
BMS9 & 1,088 & 224 & 0.21 & 800 & 1,800 & 47 \\
DES1 & 2,508 & 317 & 0.13 & 2,100 & 3,280 & 54 \\
DES2 & 2,530 & 206 & 0.08 & 3,195 & 54 \\
\hline
\end{tabular}

Notes: The table reports summary statistics for the distribution of price (\$US) across hospitals for each stent. The sample is restricted to September 2005 (middle of the sample in time) to isolate cross-sectional variation. There are $N=54$ hospitals sampled, and BMS1-3 have exited the market.

Figure 1 shows aggregate trends in quantities and prices over the sample period. In March 2004, a second DES entered the market, resulting in decreased prices and increased usage of DES. In 2006, a study questioned the safety of DES, resulting in less DES usage and less stenting overall. In the years following June 2007, this trend reversed slightly, as it became clearer that DES were not as dangerous as the study suggested. ${ }^{11}$ For the purposes of this paper, this "DES scare" helps to identify the substitution patterns between DES and BMS.

\section{Cross-Sectional Variation}

Table 1 provides price summary statistics, documenting the variation in prices across hospitals. The coefficient of variation (standard deviation over mean), a common measure of price dispersion, has a mean of 0.13 in the sample. For example, one of the best-selling stents, DES1, has a mean price of $\$ 2,508$ with a standard deviation of $\$ 317$.

\footnotetext{
${ }^{11}$ For an overview of the DES scare and its aftermath, see "Embers still smoldering from the 2006 ESC firestorm, as experts mull DES safety and efficacy" at www.theheart.org/article/996053.do.
} 
TAble 2-Market Share Variation across Hospitals

\begin{tabular}{lccccrc}
\hline \hline Stent & Mean $(\%)$ & SD $(\%)$ & SD/Mean & Min $(\%)$ & Max $(\%)$ & $\mathrm{N}$ \\
\hline BMS4 & 5 & 3 & 0.7 & 1 & 14 & 25 \\
BMS5 & 3 & 2 & 0.6 & 1 & 7 & 23 \\
BMS6 & 6 & 6 & 1.0 & 1 & 25 & 26 \\
BMS7 & 4 & 5 & 1.1 & 1 & 25 & 39 \\
BMS8 & 4 & 4 & 1.1 & 1 & 14 & 11 \\
BMS9 & 8 & 8 & 0.7 & 1 & 32 & 47 \\
DES1 & 43 & 30 & 0.7 & 2 & 93 & 54 \\
DES2 & 41 & 30 & & & 1 & 54 \\
\hline
\end{tabular}

Notes: The table reports summary statistics for the distribution of market share (percent of all stents used) across hospitals. (Average shares do not add up to 100 percent because not all stents are used by all hospitals, as documented in the last column of the table.) The table is restricted to September 2005 (middle of the sample in time) to isolate cross-sectional variation. There are $N=54$ hospitals sampled in this month, and BMS1-3 have exited the market.

These per-unit price differences translate into significant dollar amounts. A \$317 change in price results in a difference in cost of over $\$ 300,000$ per year in the mean-volume hospital, or nearly $\$ 1$ billion per year across the three million stents implanted worldwide. This is about 20 percent of the annual revenue of the global stent market.

There are many potential explanations for this price variation across hospitals. Revenue for stenting procedures varies across hospitals. The relative strength of the interventional cardiologists versus substitute treatments and the distribution of patient types will vary across hospitals as well. Also, stents are differentiated products, and doctors vary in their preferences over which stent is best to treat a given patient. These variations induce different competitive environments in different hospitals. The variation in the market shares of each stent, the number of diagnostic procedures per hospital, and the frequency with which diagnostic procedures lead to stenting, displayed in Table 2 and Figure 2, all provide a sense of this demand heterogeneity.

Prices are usually negotiated directly between each manufacturer and each hospital, and these negotiations are another potential source of the observed price variation. The typical contract is linear, specifying a price per unit for a given stent over the contract period, often one year. ${ }^{12}$ Who is involved in the negotiation and the incentives they face differ across hospitals and manufacturers, and anecdotal evidence suggests that this could also be an important source of variation in the final price.

How much these forces influence price variation, and how they affect welfare with a change to uniform pricing, is ultimately an empirical question. Estimating the unobserved variables and disentangling their effects is the purpose of the model laid out in Section II.

\footnotetext{
${ }^{12}$ Some contracts could have discrete nonlinearities, offering a lower price if the hospital uses that stent almost exclusively, say 80 percent of the time. While I do not observe the actual contracts, online Appendix A shows that there is little, if any, evidence in the data for exclusivity playing a role in the observed price variation. My demand identification approach allows for this possibility, however.
} 


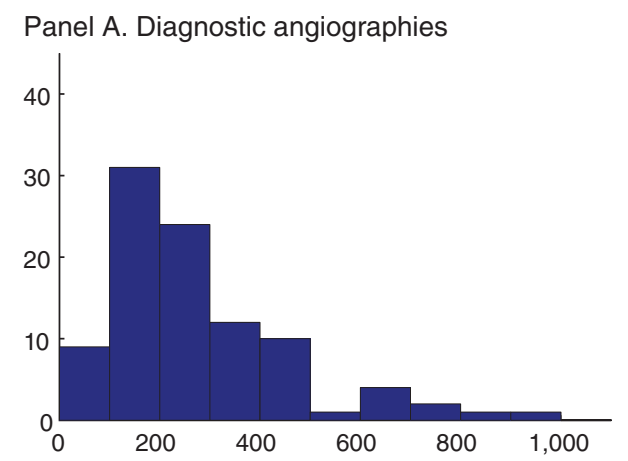

Panel B. Percent resulting in stenting

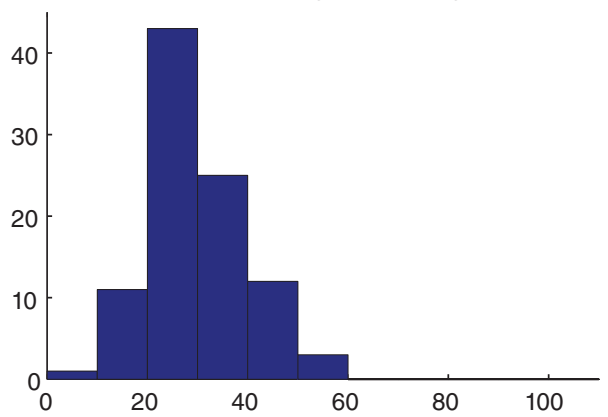

Diagnostic angiographies (procedures/hospital-month) Percent of diagnostic angiographies resulting in stenting

\begin{tabular}{rrrcrr} 
Mean & SD & Min & Median & Max & N \\
\hline 283 & 185 & 58 & 232 & 934 & 96 \\
28 & 9 & 5 & 26 & 52 & 96
\end{tabular}

Figure 2. Distribution of Procedure Volumes across Hospitals

Notes: All patients must have a diagnostic procedure to locate any blockages and detect their severity. The graph on the left shows the distribution of the average number of these procedures each hospital performs per month. The graph on the right shows the distribution of the average percentage of these procedures that result in a stenting intervention. The table below contains summary statistics for the two distributions.

Table 3-Price and Market Share Variation over Time

\begin{tabular}{lcrrrr}
\hline \hline & Mean & SD & Min & Max & N \\
\hline Change in price, $\$$ & -30 & 214 & $-1,300$ & 1,150 & 2,042 \\
Change in share, percent & 0 & 10 & -77 & 73 & 10,098 \\
Absolute change in price, $\$$ & 146 & 159 & 1 & 1,300 & 2,042 \\
Absolute change in share, percent & 5.9 & 8.1 & 0 & 77 & 10,098 \\
\hline
\end{tabular}

Notes: Summary statistics of changes over time for a given stent-hospital combination. Prices are conditional on a price change occurring. Market share is percentage of stents used.

\section{Variation over Time}

While this paper is primarily concerned with understanding the cross-sectional variation in the data, the identification strategy will rely on variation in prices and market shares over time for each stent-hospital combination. Table 3 summarizes this variation in the data. Prices change, on average, every five months, and while prices decrease slightly over time on average, there is a great deal of variation in both the direction and size of price movements. For market shares, the average change is zero, but again there is a great deal of variation around the average.

\section{Modeling Supply and Demand for Coronary Stents}

This section uses institutional details and economic theory to construct and estimate a structural model that will distinguish among and quantify the various determinants of price variation across hospitals (demand, costs, competition, and bargaining abilities). The estimated model is then used in Section IV to provide 
estimates of the welfare impact of policy changes that would limit the ability of device manufacturers to price discriminate.

The model predicts the quantities of each stent used by each hospital and the prices negotiated for each stent by each manufacturer-hospital pair in terms of a set of structural parameters that allow for heterogeneity across doctors/patients, hospitals, and time. Following Berry, Levinsohn, and Pakes (1995) and related literature, a generalized method of moments algorithm estimates these supply and demand parameters by matching the quantities and prices predicted by the model to the quantities and prices observed in the data. The main innovations in the estimation are: (i) that negotiated contracts introduce new sources of identification for demand; and (ii) the demonstration of how the assumption of price-taking buyers can be relaxed while still identifying cost and bargaining ability parameters separately.

The agents in the model are the device manufacturers who supply the products, the doctors/patients whose decisions determine demand for those products, and the hospitals that negotiate prices with manufacturers. The model is a two-stage game with no information asymmetries:

Stage 1: Pricing. Device manufacturers and hospitals contract on prices, taking expected future quantities into account.

Stage 2: Demand. Given prices and choice sets, doctors decide on stent purchases as patients arrive at the hospital.

Because the first-stage pricing equilibrium depends on expected demand, the discussion starts from the second stage and works backward.

\section{A. A Model of Demand for Coronary Stents}

I model demand using a discrete choice random utility model of how doctors choose which stent to use for each patient. This approach has the benefit of intuitively matching the doctors' decision process, and it accommodates the fact that the choice sets of available stents vary across hospitals and over time. It also allows for very flexibly shaped demand curves and the direct computation of consumer surplus measures (Nevo 2000), both of which are critical in this analysis.

A "market" is a particular hospital, $h$, in a particular month, $t$. The hospital has contracted with a set of stent manufacturers for the set of stent models $j \in \mathcal{J}_{h t}$. Over the course of a month, patients $i=1, \ldots, Q_{h t}$ arrive at the hospital to undergo a diagnostic procedure. The arrival of patients is considered exogenous to stent pricing, and thus hospitals are monopsonists of their own flow of potential stenting patients. ${ }^{13}$ The doctor chooses a treatment for each patient to maximize the following indirect utility function:

$$
\max _{j \in \mathcal{J}_{h t}} u_{i j h t}=\delta_{j h t}+\varepsilon_{i j h t},
$$

\footnotetext{
${ }^{13}$ This is consistent with the findings of Dafny (2005), which finds little evidence that hospitals compete at the diagnosis level; it finds, rather, that they instead compete in overall hospital quality.
} 
where $\delta_{j h t}$ is the mean quality of product $j$ across all patient/doctor combinations (in hospital $h$ and month $t$ ), and $\varepsilon_{i j h t}$ is a stochastic quality component with distribution $f_{h t}(\varepsilon)$, representing characteristics of the specific patient/doctor combination $i$ that make the patient an especially good candidate for a specific stent. In the spirit of Blomqvist (1991), this utility function can be thought of as a reduced form for how a doctor incorporates his own preferences, patient welfare, and hospital profitability into the treatment decision.

The set $\mathcal{J}_{h t}$ also includes a choice $j=0$ for a treatment other than stenting, and I normalize $\delta_{0 h t}=0$ so that the utility for each stent is the utility relative to the next best nonstent treatment. The most common alternative treatment would be no direct intervention (and typically a suggested diet and exercise regimen). The next most common would be coronary artery bypass graft surgery. ${ }^{14}$

The mean utility of product $j$ in hospital $h$ in month $t$ is given by

$$
\delta_{j h t}=\theta_{j h}-\theta^{p} p_{j h t}+\mathbf{X}_{j t} \boldsymbol{\theta}^{x}+\xi_{j h t},
$$

where $\theta_{j h}$ is the mean utility of product $j$ in hospital $h$ over the sample period; $\theta^{p}$ is the marginal disutility of price $p_{j h t}$ (in utils per dollar); $\mathbf{X}_{j t}$ is a matrix of month-DES interaction dummy variables starting in January 2006 to account for the scare over DES safety during this time; and $\xi_{j h t}$ are unobservable time fluctuations in hospital preferences for each stent model. ${ }^{15}$

Including the $\theta_{j h}$ fixed effects is important, as doing so controls for persistent unobserved heterogeneity at the product-hospital level (and thus also at the product level and hospital level). This heterogeneity across hospitals comes from different average preferences of doctors due to different opinions regarding the clinical data for each product, different mixes of patients, and different reimbursement levels for stenting procedures.

Because $\xi_{\text {jht }}$ is an average across different doctors with different preferences and different patients with different characteristics, however, monthly variation occurs when the sample of patients varies, when the month's patients are allocated differently among the hospital's doctors, or when an individual doctor receives information that changes her preferences. Attrition and recruitment of new doctors over time could also lead to changes in these unobserved preferences at the hospital level. To capture this, I model $\xi_{j h t}$ as evolving according to a first-order autoregressive $(\mathrm{AR}(1))$ process:

$$
\xi_{j h t}=\rho \xi_{j h t-1}+\tilde{\xi}_{j h t}
$$

where $\tilde{\xi}_{j h t}$ is the innovation in hospital preferences for product $j$ at time $t$, and $\rho$ measures the persistence (of the variation around the mean $\theta_{j h}$ ) over time. 16

\footnotetext{
${ }^{14}$ According to the Dartmouth Health Atlas, angioplasty procedures outnumbered bypass by approximately 3 to 1 in the United States in 2007, suggesting approximately 90 percent of the outside option is no intervention.

${ }^{15}$ Online Appendix C offers several robustness checks on this specification on subsamples of the data, with month dummy variables (excluded from the main specification due to evidence of attenuation bias), and with different distributional and evolution assumptions on the unobservables.

${ }^{16}$ Note that any drift component of this process is subsumed into $\theta_{j h}$. There are well-known challenges in models where dynamic processes are combined with fixed effects (for an overview, see Blundell and Bond 2000). The long
} 
Not all doctor/patient combinations at a given hospital in a given month are the same, and the model captures these differences in the doctor/patient-specific unobservable term, $\varepsilon_{i j h t}$. The distribution $f_{h t}(\varepsilon)$ is an important component of the demand estimation because it directly affects the extent to which different products are substitutes for one another. I model $f_{h t}(\varepsilon)$ as a mixture of nested logit models:

$$
\varepsilon_{i j h t}=\epsilon_{i j h t}^{s t e n t}+\left(1-\sigma_{s t e n t}\right) \epsilon_{i j h t}^{d e s}+\left(1-\sigma_{s t e n t}\right)\left(1-\sigma_{d e s}\right) \epsilon_{i j h t}+\lambda_{i j h t},
$$

where the three $\epsilon$ terms are the random coefficients representation for a two-level "nested logit" model (as derived in Cardell 1997), and $\lambda$ represents the mixing distribution; $\epsilon_{i j h t}^{\text {stent }}$ is a random component common to all stents, modeling the fact that patients vary in how badly they need a stent versus an alternative treatmentas $\sigma_{\text {stent }} \in[0,1]$ approaches 1 , there is less substitution between stents and alternatives; $\epsilon_{i j h t}^{d e s}$ is a random component common to all DES, modeling the fact that some patients will be especially suited for a DES or BMS - as $\sigma_{d e s} \in[0,1]$ approaches 1 , there is less substitution between DES and BMS; $\epsilon_{i j h t}$ and $\lambda_{i j h t}$ are random components specific to stent $j$, modeling the fact that some doctors may have very strong preferences for a particular stent for a particular patient; $\epsilon_{i j h t}$ is the standard "logit" error term (extreme value type I normalized with mean zero and scale 1). The random mean shifter, $\lambda_{i j h t}$, takes the value $\lambda_{d e s}$ or $\lambda_{b m s}$ with probability $\phi_{j h t}$ and zero otherwise. This allows the distribution of doctor/patient tastes for each stent to be bimodal, capturing the fact that a doctor may have a strong preference for a particular stent (Hastings 2008 and many papers in the marketing literature use a similar setup to characterize "brand loyalty"). Allowing for this possibility is critical because a bimodal distribution allows for a demand curve with multiple groups of consumers, each with similar willingness-to-pay, whereas a unimodal distribution does not; and these two situations have very different implications for pricing.

Market Shares and Demand Estimation.-Given this demand structure, define the set of patients for whom a doctor chooses product $j$ (in hospital-month $h t$ ) as $\mathcal{A}_{\text {jht }}:=\left\{i \mid j=\arg \max _{k \in \mathcal{J}_{h t}} u_{i k h t}\right\}$. Then expected market shares for each stent are given by the choice probability for each stent in each market:

$$
s_{j h t}=\operatorname{Pr}\left[j=\underset{k \in \mathcal{J}_{h t}}{\arg \max } u_{i k h t}\right]=\int_{A_{j h t}} f_{h t}(\varepsilon) d \varepsilon .
$$

I estimate demand for coronary stents by matching the observed market share data to the expected market shares predicted by the demand model, and using the contraction mapping from Berry, Levinsohn, and Pakes (1995) to invert this system of equations to obtain an equation that is linear in the parameters, data, and unobservable, $\xi_{\text {jht }}$. The econometric unobservable is then isolated by taking pseudodifferences (i.e., $\left.\tilde{x}:=x_{t}-\rho x_{t-1}\right)$, yielding

panel (42 months) in this dataset allows for estimation of the standard "within" estimator without the incidental parameters problem faced in small $T$ panels. 


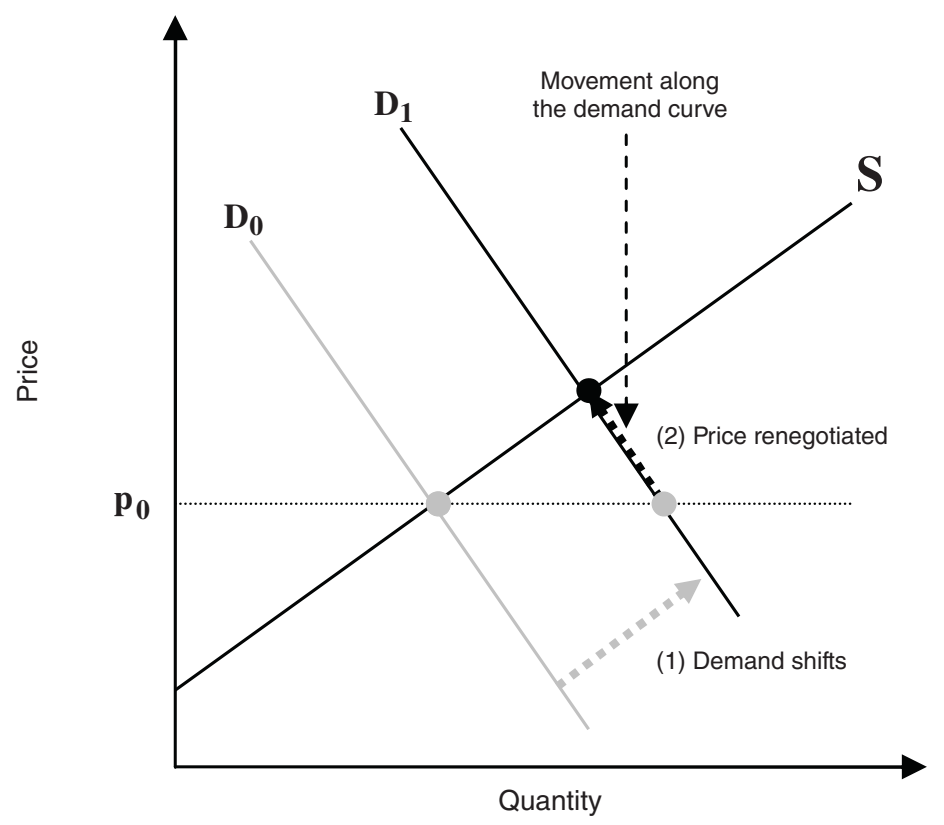

Figure 3. Fixed Price Contracts Provide a New Source of Identification

$$
\tilde{\xi}_{j h t}=\tilde{\delta}_{j}\left(\mathbf{s}_{h t} ; \sigma, \lambda, \phi\right)-\theta_{j h}(1-\rho)+\theta^{p} \tilde{p}_{j h t}-\tilde{\mathbf{X}}_{j t} \boldsymbol{\theta}^{x},
$$

which can then be interacted with a set of instrumental variables $\mathbf{Z}^{d}$ satisfying $E\left[\tilde{\boldsymbol{\xi}} \mid \mathbf{Z}^{d}\right]=0$ to estimate the demand parameters.

Demand Identification with Negotiated Prices.-The economics of negotiated prices in long-term contracts introduce two new sources of identification for demand: (i) when prices are negotiated, bargaining ability becomes available as an additional supply shifter; and (ii) when prices are fixed in long-term contracts and demand shifts over time, the observed prices and quantities will be "out of equilibrium" until price is renegotiated. When price is renegotiated, the movement will be along the demand curve, identifying demand, as illustrated in Figure 3.

Along with these sources of exogenous variation, demand identification relies on a timing assumption: that price negotiations do not anticipate and take into account future changes in demand that are not already incorporated in current demand. This assumption seems reasonable in this context because any future development that is certain enough to be taken into account in pricing negotiations seems likely to already be incorporated into current demand. Failure of this assumption would require a situation where a device salesperson knows about a forthcoming study regarding a stent, convinces the hospital purchasing negotiator that this future study will increase future demand, but keeps this information from doctors so that it does not increase current demand.

Under this identifying assumption, if new prices are always negotiated at the beginning of a month, then realized demand is a response to this new price and 
any subsequent changes in demand, and there is no simultaneity problem in using contemporaneous price as its own instrument. I take a more conservative approach, however, and construct a set of instrumental variables using one-month lags to ensure that the instruments are uncorrelated with unobservable changes in demand over time. I instrument for the price of each stent using: (i) lagged own price, which uses the economics of long-term contracts as a source of identifying variation; and (ii) the lagged average price of other stents at the same hospital, which captures supply-side variation over time in hospital bargaining ability (and also in competition as demand for other stents changes, similar in spirit to the Berry, Levinsohn, and Pakes 1995 instruments).

Similar to Lee (2009) and Sweeting (2007), these lagged values will be correlated with contemporaneous price if any of demand, cost, or bargaining ability evolve over time according to some imperfectly persistent process. Both demand and bargaining ability should do so in this application. Monthly variation in demand occurs due to changes in doctor preferences (as new studies are released and device salespeople spread the word) or doctor turnover within a hospital over time. Imperfectly persistent variation in bargaining abilities would result from changes over time in the individuals involved in bargaining for a given stent at a given hospital, changes in the incentives faced by the same individuals, or learning by the same individuals over time. Online Appendix $\mathrm{C}$ confirms that these instruments are strongly correlated with price.

The nonlinear parameters in the demand function-the mixture parameters $\left(\lambda_{b m s}, \lambda_{d e s}\right)$ and nested logit parameters $\left(\sigma_{s t e n t}, \sigma_{d e s}\right)$ - are identified by the extent to which market share responses to price changes vary nonlinearly within stent type, across stent types, and versus the outside good. To capture the nonlinearities, I use a semiparametric basis of the squares of the price instruments, lagged market shares, and their interaction. To capture the substitution patterns across groups, I use lagged logarithms of the within-stent and within-DES market shares (the standard nested logit instruments). Other regressors serve as their own instruments, as detailed in online Appendix B.

Elasticities and Surplus Measures.-The demand parameters enter the pricing model through expected quantities, elasticities, and hospital surplus measures. The maintained assumption is that all of these measures can be obtained from the revealed preference estimates of the utility parameters for how doctors incorporate their own preferences, hospital preferences, and patient preferences in choosing a treatment for each patient. Further, I assume that these utility parameters are structural in the sense that they do not change with the changes in market structure considered in Section IV.

At the time of contracting, the exact set of patients that will show up at the hospital is uncertain. So expected quantities for any given price vector $\mathbf{p}_{h t}=\left\{p_{j h t}\right\}_{j \in \mathcal{J}_{h t}}$ are anticipated via expected market shares by $q_{j h t}\left(\mathbf{p}_{h t}\right)=s_{j h t}\left(\mathbf{p}_{h t}\right) Q_{h t}$. Price elasticities, $\frac{\partial q_{j h t}}{\partial p_{k h t}} \frac{p_{k h t}}{q_{j h t}}$ and hospital surplus, $\pi_{h t}=\sum_{j \in \mathcal{J}_{h t}} \int_{A_{j h t}} \frac{u_{i j h t}}{\theta^{p}} d \varepsilon$ are similarly considered in expectation. The explicit equations for all three come from the distributional assumption on $\varepsilon$, and are thus a linear combination of the well-known equations for the nested logit, detailed in the online estimation Appendix B. 
Deriving expected quantities and elasticities in this way matches the modeling setup and reality in the stent market that the decision about how to treat each patient is made by the physician, and thus represents how that physician weights her own preferences, those of the patient, and those of the hospital. Extending this physician utility function to the hospital surplus measure that will enter pricing negotiations, though, is not an obvious step and warrants further discussion. The motivation behind this step — which says implicitly that doctors and administrators behave according to the same utility function in assessing the value of a given stent - can be best captured by a quote from an article on physician preference items in the Journal of Healthcare Contracting (2009, p.12): "In many cases, physicians-when given good data to work with-will work out supply chain issues amongst themselves in a way that pleases both the clinical and administrative sides of the house." The intuition behind this comes from the fact that, despite their different roles within the organization, in the end doctors and administrators care about many of the same things: patient health, doctor satisfaction, and hospital profitability.

What if the surplus function for administrators who negotiate prices is different than that of doctors who choose which stents to use (e.g., more price sensitive)? To the extent this is the case, it will be captured in the bargaining ability parameters in the pricing model presented in the next section. This introduces a slightly different interpretation for a high hospital bargaining ability. A high bargaining ability may result from the ability to drive a better deal with device manufacturers, or it may result from an administrator's power to maintain and act upon a more price-sensitive view of the available stents than the doctors at that hospital.

\section{B. Modeling Pricing with Competition and Bargaining}

Prices are set in a model of bargaining in the presence of competition where each hospital negotiates with each manufacturer separately and simultaneously, with the outcome of each negotiation satisfying the bilateral Nash bargaining solution. The outcomes of these bilateral negotiations must be consistent with one another, forming a Nash equilibrium in the sense that no party wants to renegotiate. Formally, prices are determined as a Nash equilibrium of bilateral Nash bargaining problems (first introduced in Horn and Wolinsky 1988). Each bilateral price maximizes the Nash product of manufacturer profits and hospital surplus, taking the other prices as given, solving

$$
\max _{p_{j h t}}\left[q_{j h t}\left(\mathbf{p}_{h t}\right)\left(p_{j h t}-c_{j h t}\right)\right]^{b_{j t}(h)}\left[\pi_{h t}\left(\mathbf{p}_{h t}\right)-d_{j h t}\right]^{b_{h t}(j)} \quad \forall j \in \mathcal{J}_{h t},
$$

where the parameters $b_{j t}(h), b_{h t}(j) \geq 0$ represent the bargaining ability of the manufacturer and hospital vis-à-vis each other, respectively, and $d_{j h t}$ is the hospital's disagreement payoff when no contract with $j$ is signed. The manufacturer's disagreement payoff is equal to marginal cost by the assumptions that the hospital is a monopsonist, the manufacturer is not capacity constrained, and each hospital is small enough that any returns to scale in manufacturing are not affected by inclusion or exclusion from a single hospital. Here I write the model with each product negotiated separately, though it is possible to allow for multiproduct manufacturers, as discussed in online Appendix BB2. 
A variation of this model has been used in prior empirical work by Crawford and Yurukoglu (2012), and many related models have been developed in theoretical work on bilateral negotiations with externalities (e.g., Stole and Zwiebel 1996; de Fontenay and Gans 2007). This prior work includes detailed discussions on how this model "nests" the solutions to many other pricing models of interest. Of particular interest here are: when the hospital has zero bargaining ability $\left(b_{h t}(j)=0, \forall j \in \mathcal{J}_{h t}\right)$, manufacturers set prices in a Bertrand-Nash price equilibrium; and when a manufacturer has zero bargaining ability $\left(b_{j t}(h)=0\right)$, that manufacturer prices at cost. Also, different assumptions on the threat points, $d_{j h t}$, correspond with different notions of bargaining. Here I follow Horn and Wolinsky (1988) and Crawford and Yurukoglu (2012), letting $d_{j h t}:=\pi_{h t}\left(\mathbf{p}_{h t} ; \mathcal{J}_{h t} \backslash\{j\}\right)$, where the parties assume that other contracts would not be renegotiated if they did not reach agreement.

The clearest way to understand the model is by taking the first-order conditions of equation (7), which yield the following pricing equation:

$$
p_{j h t}=c_{j h t}+\frac{b_{j t}(h)}{b_{j t}(h)+b_{h t}(j)} \underbrace{\left[\left(1+\frac{\partial q_{j h t}}{\partial p_{j h t}} \frac{p_{j h t}-c_{j h t}}{q_{j h t}}\right)\right.}_{\text {NTU adjustment }} \underbrace{\frac{\pi_{h t}-d_{j h t}}{q_{j h t}}+p_{j h t}-c_{j h t}}_{\text {"Added Value" of } j}],
$$

which says that equilibrium prices are equal to cost plus a margin that is the manufacturer's bargaining ability relative to that of the hospital, multiplied by product $j$ 's "added value:" the additional surplus created when the hospital contracts with product $j$ versus when the hospital doesn't contract with product $j$. The portion of the added value appropriated by the hospital is adjusted by a term that takes into account that, in this nontransferable utility (NTU) game, a dollar increase in price also results in a decrease in quantity, so it does not transfer linearly into manufacturer profits.

The model requires that the term $\frac{\partial q_{j}}{\partial p_{j}} \frac{p_{j}-c_{j}}{q_{j}}$ lies in the interval $[-1,0]$ (whereas the Bertrand-Nash case, where manufacturers set price, requires that it be exactly negative one). ${ }^{17}$ This requirement means that, taking the prices in other negotiations as given, equilibrium prices must fall in the range where each manufacturer would prefer to increase price and the hospital would prefer to decrease price. Thus, prices are always between marginal cost and the manufacturer's Bertrand-Nash best-response price.

Competition between substitutes enters this model in two ways: (i) via the hospital's disagreement point of not contracting with a given product; and (ii) via the elasticities. The constraint of the hospital's disagreement point is reminiscent of solutions such as the Core, whereas the elasticities are directly related to standard models of price competition with differentiated products. ${ }^{18}$ Via these two effects,

\footnotetext{
${ }^{17}$ Algebraic manipulation of the pricing equation gives $p-c=\frac{b_{j}}{b_{h}}\left(1+\frac{\partial q}{\partial p} \frac{p-c}{q}\right) \frac{\pi-d}{q}$. For price above cost and $d_{j h}=\pi_{h}(p ; \mathcal{J} \backslash\{j\})$, all the components of this equation are positive, requiring that $1+\frac{\partial q}{\partial p} \frac{p-c}{q}>0$ as well.

${ }^{18}$ Another way to see the connection between the two models is to look at the "elasticity pricing rule" generated by this model, $\frac{p_{j}-c_{j}}{p_{j}}=\frac{1}{-\frac{\partial q_{j}}{\partial p_{j}} \frac{p_{j}}{q_{j}}+\frac{b_{h}(j)}{b_{j}(h)} \frac{p}{\left(\pi_{h}-d_{j h}\right) / q_{j}}}$, which is the same as the one from the Bertrand-Nash model when $b_{h}=0$.
} 
more "competition," such as lower prices or greater substitutability among products, decreases both the added value and NTU adjustment terms, leaving a smaller piece of the pie for product $j$ to capture. Conditional on competition, however, the amount of value captured depends on bargaining via $\frac{b_{j}(h)}{b_{j}(h)+b_{h}(j)}$.

Bargaining Effects in Nonuniform versus Uniform Pricing.-This model also clarifies how bargaining enriches the set of forces that need to be considered when considering nonuniform (discriminatory) prices versus more uniform pricing regimes. The counterfactual simulations of GPOs and hospital mergers in Section IV allow for negotiation of a single price for each stent $j$ with a set of hospitals $h \in \mathcal{H}$. Looking at the pricing equation that emerges in this case (where the bar above a term denotes the quantity-weighted average over hospitals; e.g., $\left.\overline{x_{j h}}:=\sum_{h} \frac{q_{j h}}{\sum_{h} q_{j h}} x_{j h}\right)$ :

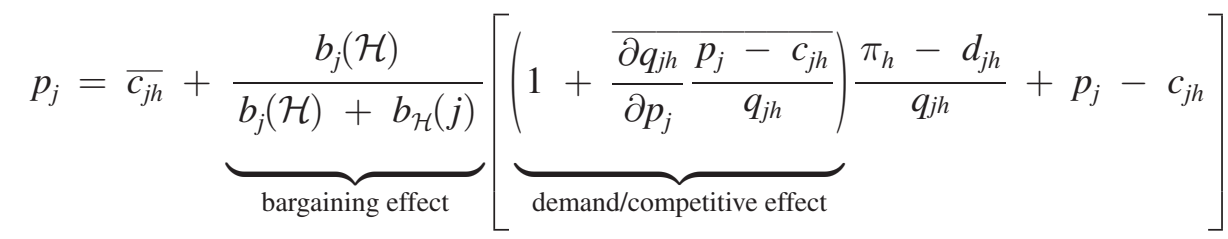

illustrates how the uniform case in equation (9) differs from the nonuniform case in equation (8) in two important ways. First, under nonuniform pricing the critical demand parameters are the product-hospital elasticities, whereas under uniform pricing the relevant elasticity is a quantity-weighted average of these elasticities. This is the term underlying the competitive effects discussed in the price discrimination literature. Second, in the nonuniform case the key bargaining term is the product-hospital bargaining ratio, whereas under uniform pricing, the bargaining ratio is the same across all hospitals. This bargaining effect is new, and it interacts with the competitive effect: for a change from nonuniform to uniform pricing, the role of symmetry in demand increases as the hospital group bargaining ability increases. The estimates in Section IV suggest that both competitive and bargaining effects play quantitatively important roles in understanding the impact of GPOs and hospital mergers on stent prices.

Pricing: Identification and Estimation.-This section shows how this pricing model can be combined with the demand estimates in order to estimate costs and relative bargaining abilities. The quantities to be estimated in the pricing equation (8) are costs, $c_{j h t}$, and the relative bargaining ability ratio $\frac{b_{h t}(j)}{b_{j t}(h)}$. A full statistical model requires specifications for costs and bargaining in terms of data, parameters, and unobservables. Because the full distributions of $c_{j h t}$ and $\frac{b_{h t}(j)}{b_{j t}(h)}$ are not separately identified, one of these specifications must be entirely in terms of data and parameters - no unobservables (estimating both distributions without restriction would be analogous to attempting to estimate separate slope and intercept parameters for every observation in a linear regression). 
I specify manufacturer marginal costs by

$$
c_{j h t}=\gamma_{j}=\gamma_{b m s} \mathbf{1}_{\{j=b m s\}}+\gamma_{d e s} \mathbf{1}_{\{j=d e s\}},
$$

so that cost is determined entirely by whether the stent is a BMS or DES. Ideally, marginal costs would be stent-specific, but the data in this study is not able to identify a more flexible specification. This issue, and the robustness of the paper's results to cost estimates, are discussed at length in the results. I further assume that there are no unobservable determinants of costs. This assumption seems reasonable in this context because marginal costs of production and distribution are thought to be quite low and to vary little (if at all) for a given product across hospitals and time. Also, it allows me to estimate the full distribution of relative bargaining abilities, which I am specifically interested in for this study.

For relative bargaining ability, I specify

$$
\frac{b_{j t}(h)}{b_{h t}(j)}=\beta_{j h} \nu_{j h t},
$$

where $\beta_{j h}$ measures the average relative bargaining ability of stent $j$ to hospital $h$, capturing firm-specific features (such as hospital size) as well as allowing for different bargaining abilities for the same hospital across manufacturers and vice versa; $\nu_{j h t}$ is the econometric unobservable term that measures the extent to which bargaining outcomes in the data deviate from the outcomes suggested by the pair-specific bargaining abilities; $\nu_{j h t}$ could represent the evolution of bargaining abilities over time (due to learning, changes in personnel, or changes in organizational incentives) or the possibility that bargaining outcomes are simply random (due to idiosyncratic events that might affect a particular negotiation). To the extent that bargaining outcomes vary a great deal over time, this specification will set $\beta_{j h}=1$, and all variation will be due to the random unobservable term $\nu_{j h t}$.

Estimation of Costs and Bargaining Abilities.-Combining the cost and bargaining specifications with the pricing equation gives the statistical model

$$
p_{j h t}=\gamma_{j}+\beta_{j h} \nu_{j h t}\left[\left(1+\frac{\partial q_{j h t}}{\partial p_{j h t}} \frac{p_{j h t}-\gamma_{j}}{q_{j h t}}\right) \frac{\pi_{h t}-d_{j h t}}{q_{j h t}}\right]
$$

and rearranging and taking logarithms so that the unobservable enters linearly gives

$$
\ln \left(g\left(X_{j h t}^{s} ; \gamma\right)\right)=\ln \left(\beta_{j h}\right)+\ln \left(\nu_{j h t}\right)
$$

where $g\left(X_{j h t}^{s} ; \gamma\right):=\frac{p_{j h t}-\gamma_{j}}{\left(1+\frac{\partial q_{j h t}}{\partial p_{j h t}} \frac{p_{j h t}-\gamma_{j}}{q_{j h t}}\right) \frac{\pi_{h t}-d_{j h t}}{q_{j h t}}}$ is the ratio of the amount of per-unit added value that goes to the hospital to the amount that goes to the manufacturer, adjusted by the elasticity term to account for NTU. Then the cost and bargaining 
parameters can be estimated based on the assumption $E\left[\ln (\boldsymbol{\nu}) \mid \mathbf{Z}^{s}\right]=0$ for a set of instrumental variables $\mathbf{Z}^{s}$. A detailed discussion of the estimation procedure can be found in online Appendix B.

Pricing Instruments and Identification.-The statistical model (12) based on the pricing equation shows clearly how the cost and bargaining ability parameters are separately identified: cost enters price as a constant term, while the relative bargaining abilities of the manufacturer-hospital pair are identified by the extent to which price changes as the added value of the stent changes. The only potential problem is that added value can change in response to supply shifts as well as demand shifts because in this NTU game added value is a function of price (and thus bargaining abilities and costs). Higher bargaining ability can lead to a higher price and lower added value, biasing $\beta_{j h}$ downward. This is the supply side of the simultaneity problem.

While this is a potentially large problem in theory, I expect it to be small in this context for two reasons: First, allowing for stent-hospital-specific bargaining parameters controls for fixed stent-hospital differences, meaning that the variation in unobserved bargaining ability is within stent-hospital and thus likely to be less of a problem than if variation across hospitals were used. Second, industry knowledge predicts (and demand estimates in the next section confirm) that prices play a relatively small role in driving substitution between products in this market, so the decrease in added value for an increase in bargaining ability (the mechanism that causes the potential bias) should be small.

Fortunately, the panel data and the fact that demand realizations are observed much more frequently than price renegotiations again offer an instrumental variables strategy to form predictions of the added value that are not correlated with a simultaneous change in bargaining ability. Similar to the functions of lagged shares on the demand side, lagged added value will be a valid instrument if any of cost, bargaining abilities, or demand evolve according to imperfectly persistent processes. The exogeneity of these instruments again relies on a timing assumption: that demand does not change in response to anticipated future changes in bargaining abilities.

\section{Estimation Results}

In this section, I discuss the estimates obtained via the framework developed in Section II. I first present the demand and cost parameters and compare these to external data sources as a way to check that the model captures the industry in a realistic way. The results show that heterogeneity in demand and bargaining ability both play an important role in the observed price variation.

\section{A. Demand Parameters}

The demand parameters are a critical piece of the model because they give the distribution of preferences for each stent across hospitals and across doctors/patients within each hospital. These preferences relate directly to own and cross-elasticities, consumer surplus, and added value measures that enter the industry model and welfare analysis. This section discusses those quantities directly for the preferred demand model. Online Appendix C presents the utility parameter estimates 
TABle 4-Own- and Cross-Elasticity Estimates

\begin{tabular}{|c|c|c|c|c|c|}
\hline Price elasticity of $q_{j}$ : & With respect to $p_{k}$ : & Mean & $\mathrm{SD}$ & Min & Max \\
\hline \multirow[t]{3}{*}{ BMS } & Own & $\begin{array}{c}-0.32 \\
(0.03)\end{array}$ & $\begin{array}{c}0.07 \\
(0.01)\end{array}$ & $\begin{array}{c}-0.70 \\
(0.07)\end{array}$ & $\begin{array}{c}-0.09 \\
(0.01)\end{array}$ \\
\hline & Other BMS & $\begin{array}{c}0.02 \\
(0.00)\end{array}$ & $\begin{array}{c}0.02 \\
(0.00)\end{array}$ & $\begin{array}{c}0.00 \\
(0.00)\end{array}$ & $\begin{array}{c}0.47 \\
(0.03)\end{array}$ \\
\hline & DES & $\begin{array}{c}0.12 \\
(0.01)\end{array}$ & $\begin{array}{c}0.14 \\
(0.01)\end{array}$ & $\begin{array}{c}0.00 \\
(0.00)\end{array}$ & $\begin{array}{c}1.70 \\
(0.06)\end{array}$ \\
\hline \multirow[t]{3}{*}{ DES } & Own & $\begin{array}{r}-0.52 \\
(0.04)\end{array}$ & $\begin{array}{c}0.11 \\
(0.01)\end{array}$ & $\begin{array}{c}-0.99 \\
(0.09)\end{array}$ & $\begin{array}{c}-0.09 \\
(0.01)\end{array}$ \\
\hline & BMS & $\begin{array}{c}0.01 \\
(0.00)\end{array}$ & $\begin{array}{c}0.01 \\
(0.00)\end{array}$ & $\begin{array}{c}0.00 \\
(0.00)\end{array}$ & $\begin{array}{c}0.24 \\
(0.01)\end{array}$ \\
\hline & Other DES & $\begin{array}{c}0.01 \\
(0.00)\end{array}$ & $\begin{array}{c}0.02 \\
(0.00)\end{array}$ & $\begin{array}{c}0.00 \\
(0.00)\end{array}$ & $\begin{array}{c}0.20 \\
(0.01)\end{array}$ \\
\hline \multirow[t]{2}{*}{ Outside alternative } & BMS & $\begin{array}{c}0.01 \\
(0.00)\end{array}$ & $\begin{array}{c}0.01 \\
(0.00)\end{array}$ & $\begin{array}{c}0.00 \\
(0.00)\end{array}$ & $\begin{array}{c}0.12 \\
(0.01)\end{array}$ \\
\hline & DES & $\begin{array}{c}0.08 \\
(0.01)\end{array}$ & $\begin{array}{c}0.07 \\
(0.01)\end{array}$ & $\begin{array}{c}0.00 \\
(0.00)\end{array}$ & $\begin{array}{c}0.60 \\
(0.05)\end{array}$ \\
\hline
\end{tabular}

themselves across several specifications used to determine the robustness and appropriateness of the one used here.

Demand Elasticities.-Table 4 shows the distributions of the elasticities for each type of stent across stents, hospitals, and months. ${ }^{19}$ The own-elasticity estimates vary across particular stents and hospitals, but in all cases they are quite low, with means -0.32 for BMS and -0.52 for DES. The small elasticities do not appear to be due to a failure of the demand identification strategy. As detailed in online Appendix C, the stent-hospital fixed effects, $\operatorname{AR}(1)$ disturbance, and instruments do an effective job of increasing the estimated price sensitivity compared to more naive approaches. Additionally, these small elasticities are consistent with two qualitative facts in the stent market: (i) doctors are not very price-sensitive, and (ii) prices are negotiated.

Price enters the doctor's choice of treatment for a given patient because of pressure from administrators for doctors to take price into account where it is reasonable to do so. The small elasticity estimates show that price does matter in treatment choice, but relatively little. This is consistent with how industry participants describe doctor behavior, especially for physician preference items like coronary stents. It is also consistent with the limited evidence from previous studies that suggest physicians and hospitals are relatively insensitive to financial incentives: Gaynor, Rebitzer, and Taylor (2004) find health maintenance organizations are able to reduce costs by 5 percent through physician incentive programs; and Dafny (2005) finds little evidence that hospitals adjust intensity or quality of care in response to changes in diagnosis-specific prices.

\footnotetext{
${ }^{19}$ When interpreting the elasticity estimates, it is useful to keep in mind that on average, DES prices are about two and a half times (and shares about six times) those of BMS. For example, the largest cross-elasticity is for BMS with respect to DES price, but this is not because of increased substitution on this dimension. It is because quantities for BMS are small and prices for DES are large, so that a small percentage change in DES price tends to have a larger effect on BMS quantity in percentage terms.
} 
Table 5-Added Value Estimates

\begin{tabular}{lccccr}
\hline \hline & Mean $(\$)$ & SD $(\$)$ & $\operatorname{Min}(\$)$ & $\operatorname{Max}(\$)$ & $N_{H_{j}}$ \\
\hline BMS4 & 3,916 & 265 & 3,410 & 4,345 & 25 \\
& $(425)$ & $(30)$ & $(40)$ & $(48)$ & \\
BMS5 & 3,681 & 232 & 3,385 & 4,325 & 23 \\
& $(410)$ & $(17)$ & $(39)$ & $(43)$ & \\
BMS6 & 3,874 & 323 & 3,312 & 4,770 & 26 \\
& $(426)$ & $(38)$ & $(36)$ & $(49)$ & \\
BMS7 & 3,872 & 286 & 3372 & 4,798 & 39 \\
& $(417)$ & $(32)$ & $(38)$ & $(53)$ & \\
BMS8 & 3,811 & 461 & 3,272 & 4,860 & 11 \\
& $(405)$ & $(27)$ & $(36)$ & $(43)$ & \\
BMS9 & 4,163 & 441 & 3,539 & 5,840 & 47 \\
& $(441)$ & $(44)$ & $(38)$ & $(57)$ & \\
DES1 & 6,231 & 432 & 5,386 & 7,233 & 54 \\
& $(488)$ & $(30)$ & $(43)$ & $(52)$ & \\
DES2 & 6,262 & 382 & $(4,559$ & 6,973 & 54 \\
& $(489)$ & $(37)$ & $(56)$ & \\
\hline
\end{tabular}

Notes: Summary of $\frac{\pi_{h}-d_{j h}}{q_{j h}}+p_{j h}$ estimates across hospitals for each stent. The table is restricted to September 2005 (middle of the sample in time) to isolate cross-sectional variation. There are $N=54$ hospitals sampled in this month; BMS1-3 have exited the market.

Another important point to keep in mind when interpreting the elasticity estimates is that, with negotiated prices, elasticities combine demand, competition, and bargaining abilities. In particular - as shown in Section IIIB - the bargaining model requires that $-1 \leq \frac{\partial q}{\partial p} \frac{p-c}{q} \leq 0$. Small elasticities go hand in hand with bargaining because prices are by construction lower than a price-setting supplier would set to a price-taking buyer. As a result, small elasticities could reflect low buyer pricesensitivity, low supplier bargaining ability, or a combination of both.

Willingness-to-Pay, Total Surplus, and Added Value.-The demand parameters also provide the distribution of willingness-to-pay across doctor/patient types, products, hospitals, and months via $w t p_{i j h t}=u_{i j h t} / \theta^{p}+p_{j h t}$. The sum of willingness-topay across treated patients gives the total surplus generated by stenting procedures (relative to the next best treatment, which is usually to do nothing). The mean willingness-to-pay estimate for a stenting procedure is $\$ 6,521$, which seems reasonable compared to the baseline reimbursement rate of $\$ 812$ to doctors and the Huckman (2006) estimate of $\$ 4,900$ for hospital marginal profit per angioplasty procedure. This provides another source of verification for the low price-sensitivity estimates, as greater price-sensitivity would imply lower willingness-to-pay. ${ }^{20}$ Willingness-toPay Enters the Bargaining Model through a Product's "Added Value"-The amount of extra value that is created when a hospital contracts with that product. Table 5 provides summary statistics for the distribution of expected added value (expectation over doctor/patient types) per unit, $\frac{\pi_{h}-d_{j h}}{q_{j h}}+p_{j h}$ (for now without subtracting

\footnotetext{
${ }^{20}$ For example, making all price elasticities consistent with manufacturer price-setting would require $a-1 /-0.09=11$ times increase in the price coefficient $\theta^{p}$, which would in turn imply an incredibly low mean willingness-to-pay of $\$ 593$.
} 
manufacturer marginal costs), for each product across hospitals in September 2005. The added values are nearly three times as large as prices, indicating that hospitals (and doctors and patients) capture a large part of the added value. Further, the variation in added values is small enough that some variation in costs and/or bargaining abilities will be needed to explain the observed variation in prices.

\section{B. Cost Estimates}

The pricing equation specifies price as equal to cost plus a margin that is the bargaining ability of the manufacturer relative to the hospital times the elasticityadjusted added value up for negotiation. The standard approach-assuming that suppliers set prices in a Bertrand-Nash equilibrium to price-taking buyers-is equivalent to assuming a bargaining ability of zero for buyers. In that case, the implied cost for each observation is given from the demand estimates and supply assumptions. The analysis here relaxes the supply-side assumptions to allow buyers to have bargaining abilities greater than zero. In this case, cost parameters and bargaining ability parameters are separately identified by the fact that cost is an intercept term in the pricing equation while relative bargaining ability is a slope term. The results indicate that allowing for bargaining is critical for obtaining reasonable cost estimates in the coronary stent market.

The first column in Table 6 presents the cost parameter estimates. The type-specific cost parameters - $\$ 34$ for BMS and $\$ 1,103$ for DES - are close to the range that industry experts report in the second column of the same table. ${ }^{21}$ The cost parameters are fairly imprecisely estimated, however. This is because the stent-hospitalmonth added value terms range from three to seven thousand dollars, and prices for added values near zero are the ideal data to identify the cost parameters. Without such observations, the cost parameters are identified by extrapolations far from the region of the data, and small changes in the bargaining ability (slope) estimates can lead to large changes in the cost (intercept) estimates.

The third column in Table 6 gives the cost estimates implied by assuming that manufacturers set prices in a Bertrand-Nash equilibrium, and these results point out two ways in which that model falls short. First, the mean cost estimates are unrealistically small because prices are negotiated, and to assume that manufacturers set price is equivalent to assuming that hospitals have zero bargaining ability, $b_{h}=0$, which is not the case on average. Second, the variation in cost estimates across hospitals is unrealistically large because the Bertrand model fails to allow for variation in relative bargaining abilities, forcing the variation that cannot be explained by willingness-to-pay and competition into costs. Any model with fixed bargaining abilities will produce similarly unreasonable variation in costs.

\footnotetext{
${ }^{21}$ Sources are interviews with current and former industry employees as well as Burns (2005). From a manufacturing perspective, a DES is essentially a BMS with a polymer-drug coating. The added cost of a DES is a result of the royalty paid to the drug patent owner (thought to be about $\$ 100$ per stent); the added cost of the process of adding the drug coating; and the quality of the process of adding the drug coating. This last point can be particularly important, as some industry engineers quoted yields from the coating process as 15-20 percent, meaning that only about one in six DES passes quality inspection after the coating process. The variation in these ranges reflects different experts' assumptions regarding this and other aspects of what they think should enter marginal costs.
} 
TABLE 6-Cost Estimates AND COMPARISON

\begin{tabular}{lcccc}
\hline \hline & $\begin{array}{c}\text { Bargaining } \\
\text { model }\end{array}$ & $\begin{array}{c}\text { Industry } \\
\text { experts }\end{array}$ & \multicolumn{2}{c}{ Bertrand, $b_{h}=0$} \\
\cline { 4 - 5 } & 34 & $100-400$ & $-2,211$ & Mean \\
\hline BMS cost, $\gamma_{b m s}(\$)$ & $(79)$ & & $(471)$ & SD \\
& 1,103 & $400-1,600$ & $-2,481$ & 1,325 \\
DES cost, $\gamma_{\text {des }}(\$)$ & $(286)$ & & $(660)$ & $(174)$ \\
& & & & \\
\hline
\end{tabular}

Notes: The first column reports marginal cost estimates for the bargaining model used in this paper. Column two reports a range of industry expert estimates for per-unit costs. Column three reports marginal cost estimates (mean and standard deviation across stent-hospital-months) implied by the model if manufacturers were assumed to set prices. $N=10,098$. Standard errors clustered by hospital, $N_{H}=96$.

Thus, the model estimated in this paper, which allows for bargaining and heterogeneity in bargaining abilities, yields more reasonable cost estimates. Unfortunately, the cost estimates are imprecise because the observed added value measures are large. Fortunately, the bargaining distribution and counterfactual estimates are robust to a variety of assumptions regarding costs. Online Appendix C illustrates how any unobserved cost variation would have to be unrealistically large to materially affect the results.

\section{Bargaining Distribution Estimates}

Given demand and cost estimates, the estimated distribution of relative bargaining abilities, $\beta_{j h} \nu_{j h t}$, is given by the pricing equation. This distribution is easiest to interpret when each ratio is normalized to $\frac{b_{j t}(h)}{b_{j t}(h)+b_{h t}(j)}=\frac{\beta_{j h} \nu_{j h t}}{\beta_{j h} \nu_{j h t}+1}$, which takes the value 0 when the manufacturer prices at cost, and 1 when the manufacturer sets its Bertrand best-response price.

Figure 4 shows that both of these special cases are always rejected (the minimum observed is 0.08 and maximum 0.71 ). The mean of 0.33 indicates that, on average, hospitals have greater bargaining ability parameters than manufacturers. This is in addition to the fact that, as a monopsonist, the hospital extracts surplus via competition between the stents. With standard deviation of 0.07 , however, there is significant variation around this mean. A companion paper, Grennan (2012), uses the panel structure of the data and hospital characteristics to further explore this bargaining ability variation. Importantly for this study, the panel data allows for a regression of $\ln \left(\beta_{j h} \nu_{j h t}\right)$ on manufacturer and hospital dummy variables, and the coefficients on each firm dummy variable $\left(\beta_{j}, \beta_{h}\right)$ provide a measure of the average bargaining ability of each firm across bargaining partners and over time. These firmspecific bargaining abilities play an important role in calculating the expected prices under GPOs and mergers in Section IV.

\section{The Welfare Effects of More Uniform Pricing}

The results in the previous section indicate that the observed price variation across hospitals for a given stent comes from variation in both demand and bargaining 


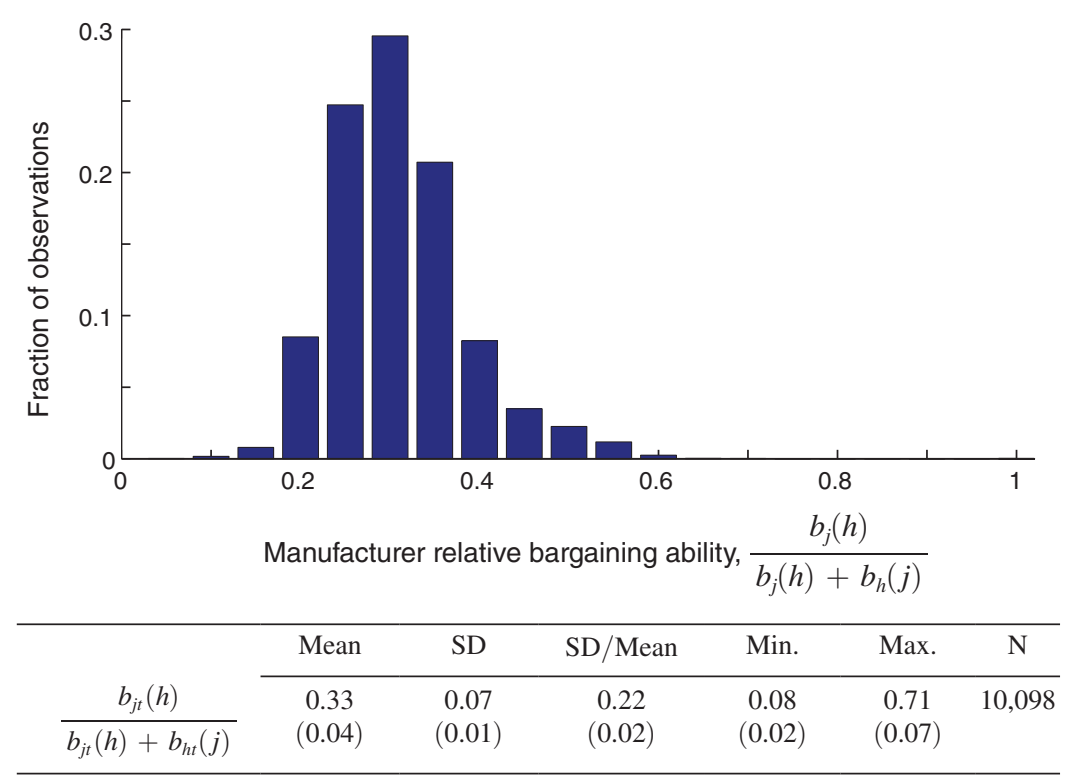

Figure 4. Distribution of Manufacturer Relative Bargaining Abilities, $\frac{b_{j t}(h)}{b_{j t}(h)+b_{h t}(j)}$

Notes: Overall product-hospital-time observations. The measure takes the value 0 in the case where the hospital gets all the surplus (conditional on disagreement points) and the manufacturer prices at cost; and it takes the value 1 in the case where the manufacturer gets all the surplus, pricing at the highest price consistent with competition. Standard errors in parentheses, clustered by hospital.

abilities. Both of these sources of heterogeneity also play an important role in this section, which examines several counterfactual scenarios with more uniform pricing, including: uniform prices set by manufacturers (a potential outcome of transparency reforms); centrally negotiated pricing for all hospitals (via GPOs or government purchasing); and negotiated prices at the level of merged hospital systems. The analysis makes clear that the details of how more uniform prices are implemented matter a great deal for whether or not prices for stents would rise or fall. Two particularly important forces that play a role in all cases are the effect of a move to more uniform prices on: (i) the intensity of competition; and (ii) whether buyers are able to negotiate, and if so, at what bargaining ability.

The effect of imposing uniform pricing on the intensity of competition is closely related to what the price discrimination literature calls "best-response (a)symmetry" (Robinson 1933; Corts 1998). If demand across hospitals for the different stents is symmetric in the sense that all stents prefer to set a higher price to the same hospitals (e.g., because compared to alternative treatments, these hospitals value all stents more than other hospitals), then a move to uniform pricing will tend to intensify competition (Holmes 1989; Stole 2007). On the other hand, if demand across hospitals is asymmetric in the sense that some hospitals prefer one stent while other hospitals prefer another (and thus different stents want to set high prices in different hospitals), then a move to uniform pricing will tend to soften competition as stent suppliers retreat to their more captive markets (Corts 1998). The results in this 
section suggest that the market for coronary stents exhibits more asymmetry than symmetry in demand across hospitals, leading competition to soften and-holding all else equal-making hospitals worse off under any policy that imposes more uniform pricing.

One especially important factor that may not be held equal, however, is the impact of a change to more uniform pricing on bargaining abilities. Section IIB illustrated how this bargaining effect could play an important role in theory. The results in this section suggest that it plays an important quantitative role: in order to reduce stent prices, any change to more uniform pricing must also induce a (potentially large) increase in hospital bargaining ability.

The welfare effects of the various market interventions considered in the rest of this section depend upon exactly how that intervention triggers changes to competition and/or bargaining ability. A straightforward imposition of uniform pricing (either by mandate or perhaps indirectly through transparency measures) would both soften competition and remove hospitals' ability to negotiate. More centralized purchasing (either through government or private group purchasing organizations) would suffer from softened competition, but has the opportunity to make up for this through increased bargaining ability. Mergers highlight the complementarity between bargaining ability and symmetry of demand-while the competitive effect encourages mergers between hospitals with more symmetric variation in demand, the return to symmetry is increasing in the bargaining ability of the merged hospital group.

\section{A. Centralized Pricing: Competitive and Bargaining Effects}

In all of the counterfactual scenarios, prices are set according to a Nash equilibrium of Nash bargaining problems, as before; however, now there is only one price for each stent across the set $\mathcal{H}$ all hospitals (or for mergers in the next section, a subset of hospitals), so product and hospital profits are aggregated over hospitals. This has an interpretation of the hospitals bargaining collectively with each manufacturer, and the outcomes of these negotiations forming an equilibrium with one another, solving

$$
\max _{p_{j}}\left[\sum_{h \in \mathcal{H}} q_{j h}\left(p_{j}-c_{j}\right)\right]^{b_{j}}\left[\sum_{h \in \mathcal{H}}\left(\pi_{h}-d_{j h}\right)\right]^{b_{\mathcal{H}}} \quad \forall j \in \mathcal{J}
$$

where $b_{\mathcal{H}}$ is a bargaining parameter for all the hospitals collectively. Table 7 compares the aggregate outcomes from the current price discrimination regime to counterfactual predictions under uniform pricing for three different values of the hospital group bargaining ability- $b=0, \overline{\beta_{h}}$, and $\max \left(\beta_{h}\right)$. In all cases, manufacturer bargaining abilities are set to their estimated means versus all hospitals, $b_{j}=\beta_{j}$.

The most dramatic change occurs if hospitals are unable to bargain collectively $\left(b_{\mathcal{H}}=0\right)$. This could result from direct imposition, or, more likely, as a result of efforts to increase price transparency. There has been an active yet inconclusive policy debate on transparency in device pricing, with much of Issue 27, 2008, of Health Affairs devoted to the topic. While there are theoretical discussions on both sides of this issue, to my knowledge this is the first related empirical analysis. If, as Armstrong (2006) suggests, it is exactly the lack of transparency that allows sellers 
TABle 7-EFfects of Changing to Uniform Pricing

\begin{tabular}{lcccc}
\hline \hline & & \multicolumn{3}{c}{ Percent change with uniform prices } \\
\cline { 2 - 5 } & Current regime & $b_{\mathcal{H}}=0$ & $b_{\mathcal{H}}=\bar{\beta}_{h}$ & $b_{\mathcal{H}}=\max \left(\beta_{h}\right)$ \\
\hline Manufacturer profits (\$M/hospital/year) & 1.24 & 81 & 8 & -15 \\
& & $(27)$ & $(1)$ & $(3)$ \\
Hospital surplus (\$M/hospital/year) & 4.32 & -48 & -1.4 & 7.2 \\
& $(0.58)$ & $(2)$ & $(0.3)$ & $(0.5)$ \\
Total surplus (\$M/hospital/year) & 5.56 & -19 & 0.7 & 2.2 \\
& $(0.75)$ & $(1)$ & $(0.1)$ & $(0.2)$ \\
Total stentings (stents/hospital/year) & 977 & -43 & -1.1 & 5.9 \\
& & $(2)$ & $(0.3)$ & $(0.4)$ \\
Mean BMS price (\$/stent) & 1,016 & 207 & 1.7 & -25 \\
& & $(35)$ & $(0.4)$ & $(1.6)$ \\
Mean DES price (\$/stent) & 2,509 & 114 & 1.7 & -14 \\
& & $(14)$ & $(0.7)$ & $(0.9)$ \\
\hline
\end{tabular}

Notes: Standard errors in parentheses, clustered by hospital. Equilibrium outcomes under the current negotiated price regime compared to those under uniform pricing (e.g., GPO of all hospitals in sample) for September 2005. Column 2 sets $b_{\mathcal{H}}$ to zero, the case where hospitals do not bargain collectively and manufacturers set prices. Column 3 sets bargaining ability of the group of hospitals, $b_{\mathcal{H}}$, to the mean of individual hospitals, $\overline{\beta_{h}}$, in order to isolate the change to competition. Column 4 sets $b_{\mathcal{H}}$ to the maximum estimated bargaining ability of any individual hospital.

to cut the "secret discounts" that lead to different hospitals paying different prices, then increasing transparency could provide manufacturers a mechanism to commit to take-it-or-leave-it uniform pricing. ${ }^{22}$

To the extent that price transparency would lead to this outcome, it would have exactly the opposite effect that policymakers concerned with hospital costs are looking for. I estimate that a move to uniform pricing with price-taking hospitals would cause prices and manufacturer profits to approximately double; hospital surpluses to decrease by 48 percent (profits 160 percent); ${ }^{23}$ and total surpluses to decrease by 19 percent. This large predicted price increase results from the fact that doctor/patient/hospital demand is estimated to be rather insensitive to price, and this counterfactual takes aways hospitals' ability to negotiate price. Prices at more than double the observed level are well outside the observed range of data (in particular, the equilibrium between administrators and doctors that induces doctor price sensitivity could be very different here), so these exact numbers should be taken with some skepticism. However, the robust takeaway is that any policy that removes the hospitals' power to negotiate would likely increase the prices hospitals pay for stents.

More Uniform Prices Means Less Competition.-The $b_{H}=0$ case is an extreme one in that it forces hospitals to become price-takers. In contrast, many implemented

\footnotetext{
${ }^{22}$ One could imagine transparency having effects other than the extreme case analyzed here. A full analysis of the effect of transparency or other mechanisms such as most-favored-nation clauses would require a model of how these variables influence bargaining ability as well as data to identify how much. Such an analysis is beyond the current theoretical frontier and also beyond the data available here.

${ }^{23}$ Using detailed accounting data for hospitals in New York state, Huckman (2006) finds that marginal profits for angioplasty are, on average, 30 percent of revenues. I use this number to get ballpark estimates for the change in hospital profits implied by the surplus changes predicted by my model.
} 
and proposed interventions in healthcare purchasing involve more centralized pricing that enforces uniform prices across large groups of hospitals, but also create a central purchasing authority that is able to negotiate on behalf of the "merged" group. In these cases with centralized negotiations, the results are more nuanced. Because there is little substitution to alternative treatments due to moderate changes in stent prices, the effects on the total number of stentings and total welfare are small. As a result, the interesting changes are in the way the surplus is split between the device manufacturers and hospitals, and these changes are driven by a combination of the competitive and bargaining effects.

The results when hospitals bargain collectively at the mean bargaining ability of all the hospitals, $b_{\mathcal{H}}=\overline{\beta_{h}}$, isolate the competitive effect and show how competition softens under uniform pricing. Prices increase by 2 percent on average; manufacturer profits increase by 8 percent; and hospital surplus decreases by 1.4 percent (profits 5 percent). ${ }^{24}$

This competitive effect is consistent with the theoretical results on best-response asymmetry (Corts 1998) as well as the reduced-form evidence in Section II regarding the amount of asymmetry across hospitals in the market share data. It is also consistent with related studies in the gasoline (Hastings 2008) and coffee markets (Villas-Boas 2009), which also find that prices increase with a change to nondiscrimination. The hospital merger experiments in Section IVB explore this competitive effect in greater detail, using variation in the amount of symmetry among groups of merging hospitals to quantify the relationship between symmetry and post merger hospital profits. Before exploring the competitive effect further, though, the last column of Table 7 sheds light on a feature that has not been noted before: the effect of bargaining ability on a change to more uniform pricing.

The Bargaining Effect: Post "Merger" Bargaining Ability Matters.-The competitive effect of merging demand across hospitals with asymmetric preferences works to raise prices, but the final price in any centralized purchasing scheme will depend on the bargaining ability of the "merged" group of hospitals. Allowing the group to have the maximum estimated bargaining ability across all hospitals, $b_{\mathcal{H}}=\max \left(\beta_{h}\right)$, is enough to overcome the competitive disadvantage. In this case, prices and manufacturers' profits fall by 14 percent and 15 percent; and hospital surplus increases by 7.2 percent (profits 24 percent).

Figure 5 provides a more precise perspective on the competitive and bargaining effects. The group of hospitals would need a bargaining ability more than 7 percent larger than the average hospital (or above the 70th percentile of all hospitals) in order to overcome the disadvantage due to softer competition. Below this, hospitals would be worse off with group purchasing; above this, better off. The fact that only 30 percent of hospitals have such a high bargaining ability speaks to how difficult it might be to obtain.

\footnotetext{
${ }^{24}$ Setting the group bargaining ability to the average across hospitals is not a perfect way to isolate the change due to competition because there are still two changes. A cleaner measure is to do the change in two steps: first, let all hospitals negotiate their own prices, but with their bargaining abilities fixed at the average; second, have them negotiate as a group. The difference between the results in steps one and two isolates the true competitive effect. When I computed this, I found that the pure competitive effect accounts for over 90 percent of the change in prices.
} 


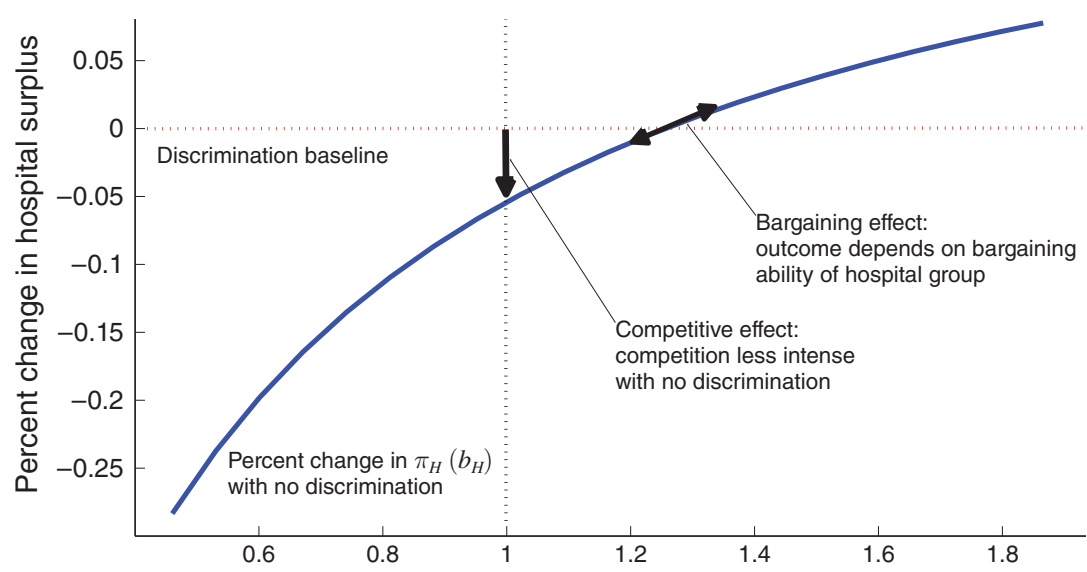

Bargaining ability of hospital group (relative to mean hospital), $b_{\mathcal{H}} / \overline{b_{h}}$

Figure 5. Competitive ANd BARgaining EFFEcts

Notes: The vertical axis is the percent change in hospital profits, and the horizontal axis is the bargaining ability of the hospital group as a ratio of the mean hospital bargaining ability. The upward-sloping curve shows the relationship between the predicted hospital profits under uniform pricing and hospital bargaining ability.

The importance of this bargaining effect underscores how thinking about heterogeneity in bargaining abilities is important not only for understanding the prices negotiated by individual hospitals, but also for calculating expected outcomes under more uniform pricing. Looking back to the previously conjectured sources of bargaining abilities in the coronary stent market offers some guidance on how to think about the issue, but no solid prediction. To the extent that bargaining ability reflects actual negotiating skill of the individual purchasing administrator or the organizational incentive system in which that individual operates, it might stand to reason that the best individuals and practices could be employed by a centralized purchasing group, leading to higher bargaining ability. On the other hand, to the extent that a large purchasing group might involve more bureaucracy and less influence with physicians, then bargaining ability might decrease. Unfortunately, the data is not available to directly address these effects in this study.

There are, however, external sources that provide some indication of the direction the combined competitive and bargaining effects take when large centralized purchasing groups are created. Looking at the data in Spain, the European Union (EU) country with the most centralized purchasing system, shows a low coefficient of variation of 0.06 but a high (relative to other EU countries) mean of $\$ 2,313$ for DES2 across hospitals. Germany, which by contrast has a mostly decentralized purchasing system, shows a higher coefficient of variation of 0.16 and a lower mean of $\$ 1,649$ for the same stent in the same month. While this evidence is not systematic, it does show that more centralization in purchasing is not necessarily accompanied by enough bargaining ability to drive down prices relative to a decentralized system. Similar evidence exists for the United States in the fact that hospital group GPOs play little to no meaningful role in the markets for coronary stents and other "physician preference items" (Burns and Lee 2008). The analysis here offers an 
explanation for this: GPOs are unable to achieve enough of an increase in bargaining ability to overcome the competitive disadvantage created by aggregating demand across hospitals with asymmetric demand. Thus, GPOs are not able to provide value when it comes to physician preference items, where different doctors have brand loyalties to different manufacturers.

\section{B. Hospital Mergers: Quantifying the Role of $(A)$ symmetry}

The results thus far are consistent with the theory that predicts more asymmetry softens competition under uniform pricing because manufacturers retreat to their captive markets. In real-world empirical settings, however, there is no such thing as complete symmetry or asymmetry, only some measure of one versus the other. Better understanding and quantifying this effect becomes especially important for thinking about hospital mergers because mergers may vary in the extent to which the merging hospitals exhibit (a)symmetry in their demand. This section develops a measure of demand symmetry among a group of buyers and quantifies the role of more or less symmetry in the context of hospital mergers into multihospital systems.

Of the 5,008 registered US community hospitals, 2,921 are part of a multihospital system, with an average of 7 hospitals per system. ${ }^{25}$ The argument in favor of hospital mergers into systems often includes arguments for reducing costs, but the evidence regarding whether or not they do so has been mixed (see, e.g., Dranove and Lindrooth 2003 and the literature cited therein). In particular, there has been especially little evidence for (or against) the assertion that mergers lower input costs by increasing buyer market power. This section provides evidence regarding the conditions under which hospital mergers might lower prices for coronary stents.

I examine this question by simulating 100 different mergers between groups of 7 hospitals drawn randomly from the dataset. Because the randomly selected groups of hospitals differ in their amount of symmetry in demand, these merger experiments provide a context in which to look at the impact of symmetry on the degree to which competition changes under uniform pricing. I measure symmetry among a group of hospitals by taking the across-hospital, within-stent variation in stent own-elasticities $\left(\eta_{j h}:=\frac{\partial q_{j h}}{\partial p_{j h}} \frac{p_{j h}}{q_{j h}}\right)$ explained by hospital dummy variables divided by the total stent-hospital variation, Symmetry $:=\frac{\operatorname{var}\left(\hat{\eta}_{j h}(j F E, h F E)\right)-\operatorname{var}\left(\hat{\eta}_{j h}(j F E)\right)}{\operatorname{var}\left(\eta_{j h}\right)-\operatorname{var}\left(\hat{\eta}_{j h}(j F E)\right)}$. This measure is equal to one when hospitals are perfectly symmetric (purely vertically differentiated in their demand for the different stents), and equal to zero when hospitals are perfectly asymmetric (purely horizontally differentiated). I simulate the new equilibrium prices and welfare measures after the mergers for two different assumptions on the post merger bargaining abilities: the mean, $b_{\mathcal{H}}=\bar{\beta}_{h}$, and the $\max , b_{\mathcal{H}}=\max \left(\beta_{h}\right)$, of the pre merger bargaining abilities of the merging hospitals. The outcomes of these merger experiments, shown in Figure 6, both quantify the relative size of competitive and bargaining effects, and also highlight the complementarity between the two effects.

${ }^{25}$ http://www.aha.org/aha/resource-center/Statistics-and-Studies/fast-facts.html. 

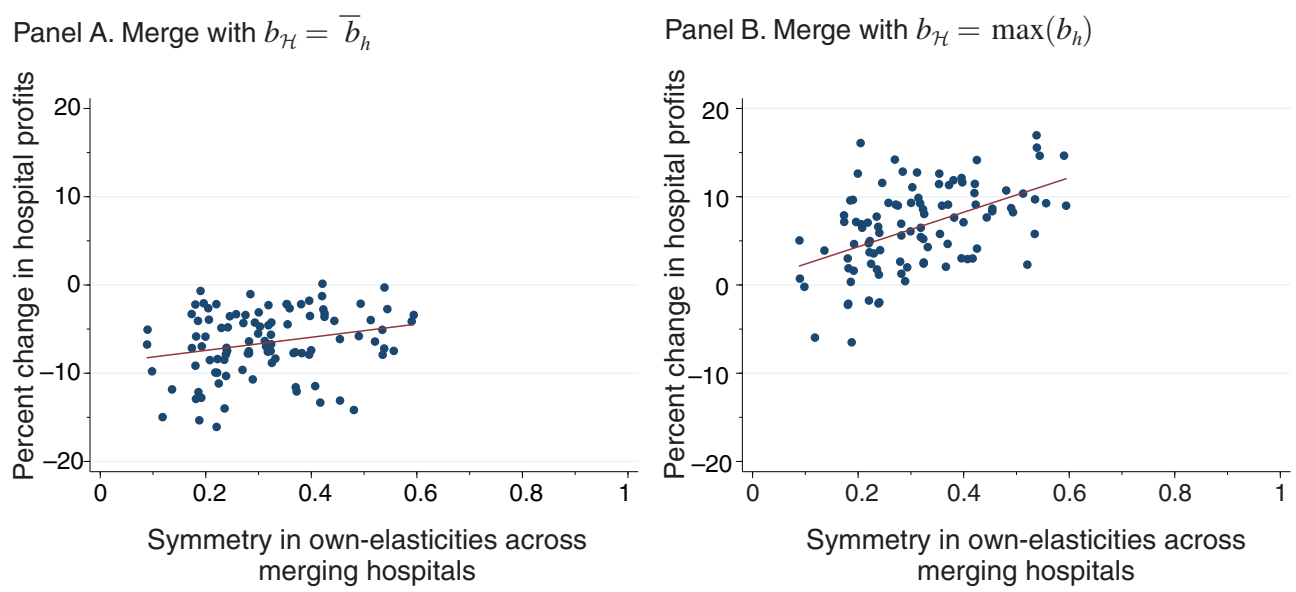

\begin{tabular}{lcc}
\hline & Merge with $b_{\mathcal{H}}=b_{h}$ & Merge with $b_{\mathcal{H}}=\max \left(b_{h}\right)$ \\
\cline { 2 - 3 } Intercept (complete asymmetry) & -8.9 & 0.42 \\
& $(1.0)$ & $(1.2)$ \\
Slope (as symmetry increases) & 7.5 & 20 \\
$R^{2}$ & $(3.0)$ & $(3.5)$ \\
Percent of mergers where hospital profits increase & 0.06 & 0.24 \\
\hline
\end{tabular}

Figure 6. Competition Softens More for Mergers between Hospitals with More Asymmetric Demand (This effect increases with bargaining ability)

Notes: Results for 100 mergers of 7 randomly selected (with replacement) hospitals. The two sets of results are for assumed post merger bargaining ability equal to mean and maximum of the merging hospitals. The vertical axis shows the pre- to post-merger change in hospital profits while the horizontal axis shows a measure of the amount of symmetry (vertical versus horizontal differentiation) in demand elasticities $\left(\eta_{j h}:=\frac{\partial q_{j h}}{\partial p_{j h}} \frac{p_{j h}}{q_{j h}}\right)$ across the merging hospitals, Symmetry $:=\frac{\operatorname{var}\left(\hat{\eta}_{j h}(j F E, h F E)\right)-\operatorname{var}\left(\hat{\eta}_{j h}(j F E)\right)}{\operatorname{var}\left(\eta_{j h}\right)-\operatorname{var}\left(\hat{\eta}_{j h}(j F E)\right)}(1$ indicates perfect symmetry; 0 asymmetry $)$.

Looking first at panel A-the case where the merged hospitals have the mean bargaining ability of the merging hospitals (isolating the competitive effect) - the fitted line predicts that a merger between hospitals with perfect asymmetry in demand would result in an 8.9 percent decrease in hospital profits. Hospital profits increase with symmetry at a slope of 7.5, predicting that a merger between hospitals with perfect symmetry would still result in a decrease of 1.4 percent in hospital profits. With an $R^{2}$ of 0.06 , the fitted line provides a noisy prediction of merger outcomes, so for very high levels of symmetry, the competitive effect will often flip and work in favor of uniform pricing. Despite this somewhat encouraging extrapolation, the data suggest that high levels of symmetry are rare-across the 100 simulated hospital groups, the maximum symmetry measure is 0.59 (mean 0.31 and minimum 0.09 ). Thus, for the highest symmetry actually observed, the competitive effect still softens competition substantially, with a predicted decrease of 4.5 percent in hospital profits.

Turning to panel $\mathrm{B}$ - the case where the merged hospitals have the maximum bargaining ability of the merging hospitals - the fitted line predicts that a merger between hospitals with perfect asymmetry in demand would result in a slight 
increase in hospital profits of 0.4 percent. Thus, the shift from mean to maximum bargaining ability was enough to erase the softening of competition for a merger of hospitals with very asymmetric preferences (though again the prediction is noisy, with an $R^{2}$ of 0.24 ). Beyond this upward shift at low levels of symmetry, a perhaps more interesting result is the complementarity between symmetry and bargaining ability demonstrated by the dramatic increase in the slope of hospital profits with respect to symmetry to 20 (more than double the slope in the mean bargaining ability case). This increased slope predicts that mergers at the highest observed levels of symmetry will now result in a 12 percent increase in hospital profits.

These results suggest that, similar to GPOs, hospital mergers need to increase bargaining ability if they are to decrease the prices hospitals pay for coronary stents. In addition, the more symmetry, the better. These insights provide some new ways to think about the mechanisms that may be behind the mixed results in research on the effect of hospital mergers on costs. Dranove and Lindrooth (2003) find that hospital mergers into systems in general have no statistically significant impact on costs, but that mergers between hospitals that subsequently do business under a single license and report unified financial records decrease costs by 14 percent on average. While at least some of the 14 percent gains of the "fully merging" cases is due to reduced headcount in redundant roles, this paper offers two additional explanations: (i) that hospitals are likely to more fully integrate postmerger when their doctors/patients/administrators exhibit less horizontally differentiated tastes; and (ii) that hospitals who integrate more fully are more likely to share best practices and learn how to maximize post merger bargaining ability.

\section{Summary and Discussion}

This paper combines new panel data on the prices and quantities transferred between medical device manufacturers and hospitals with a structural model of supply and demand to estimate the welfare effects of transparency, group purchasing, and hospital mergers in the coronary stent market. These interventions all restrict the ability of suppliers to sell at different prices to different hospitals. The major empirical challenge is that prices in the coronary stent market are negotiated (as they are in many business-to-business markets). I capture this using a model that generalizes the standard price-setting model to allow for bargaining, and I show how bargaining affects identification of both supply and demand parameters. The raw data and counterfactual estimates provide evidence that asymmetry in demand across hospitals leads to a softening of competition under more uniform pricing, consistent with the theory of price discrimination with oligopoly. Final prices under nondiscrimination also depend on the collective bargaining ability of the merged hospitals, however, which must be large to overcome the disadvantage of softened competition.

Taken together, these results suggest that moving toward more uniform pricing may be a difficult and indirect route toward lowering the prices hospitals pay for physician preference items such as coronary stents. This could be one reason why GPOs play such a small role in contracting for physician preference items and why hospital mergers often don't seem to reduce costs. If the goal is to lower the costs of medical technologies, a more fruitful approach might be to embrace the increased competition that comes with price variation and instead work directly on increasing 
bargaining ability and/or physician price sensitivity. Such an approach would be in line with the suggestion of Pauly and Burns (2008) for a focus on physicianadministrator relations.

In addition to addressing the research question at hand, this paper suggests several avenues for future research. The quantitative results here suggest that both the nature of demand heterogeneity and bargaining ability — where firms end up within the range determined by costs, demand, and competition-matter. As more detailed data on vertical contracting relationships become available, it would be interesting to see the relative roles that demand (a)symmetry and bargaining ability play in other contexts.

Relatedly, while heterogeneity in bargaining abilities across firms plays an important role in both fitting the observed data and predicting outcomes under more uniform pricing, little is known about the determinants of bargaining abilities. A companion paper, Grennan (2012), explores this issue further, but data limitations prevent more than a high-level, descriptive analysis. Anecdotal evidence from industry professionals suggests that there are economic forces such as human capital and organizational structure/incentives underlying these firm-level bargaining abilities. Better understanding the determinants of bargaining ability could lead to interesting links among internal firm activities and market outcomes. Pursuing this research topic would require detailed data related to the price negotiation process and individuals involved in addition to the price and quantity data used here.

In the long run, market interventions that make prices more uniform, like anything that affects firm profitability, could impact market entry and exit on both sides of the market. In the medical device market, this is particularly important because the buyer side represents the availability of medical care and the supplier side represents the availability of new medical technologies. Future research that takes a step toward endogenizing the choices of who contracts with whom and market entry and exit would extend our ability to answer more dynamic research questions regarding medical technologies and our understanding of the economics of business-to-business markets in general.

\section{REFERENCES}

Armstrong, Mark. 2006. "Recent Developments in the Economics of Price Discrimination." In Advances in Economics and Econometrics: Theory and Applications, Ninth World Congress Volume 2, edited by Richard Blundell, Whitney K. Newey, and Torsten Persson, 97-141. New York: Cambridge University Press.

-Berry, Steven, James Levinsohn, and Ariel Pakes. 1995. "Automobile Prices in Market Equilibrium." Econometrica 63 (4): 841-90.

Blomqvist, Ake. 1991. "The Doctor as Double Agent: Information Asymmetry, Health Insurance, and Medical Care.” Journal of Health Economics 10 (4): 411-32.

Blundell, Richard, and Stephen R. Bond. 2000. "GMM Estimation with Persistent Panel Data: An Application to Production Functions." Econometric Reviews 19 (3): 321-40.

Burns, Lawton R., ed. 2005. The Business of Healthcare Innovation. New York: Cambridge University Press.

Burns, Lawton R., and J. Andrew Lee. 2008. "Hospital Purchasing Alliances: Utilization, Services, and Performance." Health Care Management Review 33 (3): 203-15.

Cardell, N. Scott. 1997. "Variance Components Structures for the Extreme-Value and Logistic Distributions with Application to Models of Heterogeneity." Econometric Theory 13 (2): 185-213.

Corts, Kenneth S. 1998. "Third-Degree Price Discrimination in Oligopoly: All-Out Competition and Strategic Commitment." RAND Journal of Economics 29 (2): 306-23. 
Crawford, Gregory S., and Ali Yurukoglu. 2012. "The Welfare Effects of Bundling in Multichannel Television Markets." American Economic Review 102 (2): 643-85.

Dafny, Leemore S. 2005. "How Do Hospitals Respond to Price Changes?" American Economic Review $95(5): 1525-47$.

Dafny, Leemore S. 2010. “Are Health Insurance Markets Competitive?” American Economic Review 100 (4): 1399-431.

Dartmouth Atlas of Health Care. 2011. http://www.dartmouthatlas.org (accessed November, 2011).

de Fontenay, Catherine, and Joshua Gans. 2007. "Bilateral Bargaining with Externalities." Unpublished.

Dranove, David, and Richard Lindrooth. 2003. "Hospital Consolidation and Costs: Another Look at the Evidence." Journal of Health Economics 22 (6): 983-97.

Dranove, David, Mark Satterthwaite, and Andrew Sfekas. 2008. "Boundedly Rational Bargaining in Option Demand Markets: An Empirical Application.” Unpublished.

Duggan, Mark, and Fiona M. Scott Morton. 2006. "The Distortionary Effects of Government Procurement: Evidence from Medicaid Prescription Drug Purchasing." Quarterly Journal of Economics 121 (1): 1-30.

Gaynor, Martin, James B. Rebitzer, and Lowell J. Taylor. 2004. "Physician Incentives in Health Maintenance Organizations.” Journal of Political Economy 112 (4): 915-31.

Grennan, Matthew. 2012. "Bargaining Ability and Competitive Advantage: Empirical Evidence from Medical Devices." Unpublished.

Grennan, Matthew. 2013. "Price Discrimination and Bargaining: Empirical Evidence from Medical Devices: Dataset.” American Economic Review. http://dx.doi.org/10.1257/aer.103.1.145.

Hastings, Justine. 2008. "Wholesale Price Discrimination and Regulation: Implications for Retail Gasoline Prices." Unpublished.

Ho, Katherine. 2009. "Insurer-Provider Networks in the Medical Care Market." American Economic Review 99 (1): 393-430.

Ho, Katherine, Justin Ho, and Julie Holland Mortimer. 2012. "The Use of Full-Line Forcing Contracts in the Video Rental Industry." American Economic Review 102 (2): 686-719.

Holmes, Thomas J. 1989. "The Effects of Third-Degree Price Discrimination in Oligopoly.” American Economic Review 79 (1): 244-50.

Horn, Henrick, and Asher Wolinsky. 1988. "Bilateral Monopolies and Incentives for Merger." RAND Journal of Economics 19 (3): 408-19.

Huckman, Robert S. 2006. "Hospital Integration and Vertical Consolidation: An Analysis of Acquisitions in New York State." Journal of Health Economics 25 (1): 58-80.

Journal of Healthcare Contracting. 2009. "Driving Forces," November/December, p. 12.

Keehan, Sean P., Andrea M. Sisko, Christopher J. Truffer, John A. Poisal, Gigi A. Cuckler, Andrew J. Madison, Joseph M. Lizonitz, and Sheila D. Smith. 2011. "National Health Spending Projections Through 2020." Health Affairs 30 (8): 1594-1605.

Kyle, Margaret, and David Ridley. 2007. "Would Greater Transparency and Uniformity of Health Care Prices Benefit Poor Patients?” Health Affairs 26 (5): 1384-91.

Lee, Robin S. 2009. "Vertical Integration and Exclusivity in Platform and Two-Sided Markets." Unpublished.

Millennium Research Group. January 2004-June 2007. "Marketrack Survey: US Market for Interventional Cardiology." http://mrg.net/Products-and-Services/Marketrack.aspx (accessed November, 2007).

Nevo, Aviv. 2000. “A Practitioner's Guide to Estimation of Random-Coefficients Logit Models of Demand.” Journal of Economics and Management Strategy 9 (4): 513-48.

Pauly, Mark V., and Lawton R. Burns. 2008. "Price Transparency for Medical Devices." Health Affairs 27 (6): 1544-53.

Robinson, Joan. 1933. The Economics of Imperfect Competition. London: Macmillan.

Stole, Lars. 2007. "Price Discrimination in Competitive Environments." In Handbook of Industrial Organization. Vol. 3, edited by Mark Armstrong and Robert H. Porter, 2221-92. Amsterdam: Elsevier Science.

-Stole, Lars A., and Jeffrey Zwiebel. 1996. "Intra-firm Bargaining under Non-binding Contracts." Review of Economic Studies 63 (3): 375-410.

Sweeting, Andrew. 2007. "Dynamic Product Repositioning in Differentiated Product Markets: The Case of Format Switching in the Commercial Radio Industry." National Bureau of Economic Research Working Paper 13522.

Villas-Boas, Sofia Berto. 2009. "An Empirical Investigation of the Welfare Effects of Banning Wholesale Price Discrimination.” RAND Journal of Economics 40 (1): 20-46. 


\section{This article has been cited by:}

1. Martin Gaynor, Kate Ho, Robert J. Town. 2015. The Industrial Organization of Health-Care Markets. Journal of Economic Literature 53:2, 235-284. [Abstract] [View PDF article] [PDF with links]

2. Matthew S. Lewis, Kevin E. Pflum. 2015. Diagnosing Hospital System Bargaining Power in Managed Care Networks. American Economic Journal: Economic Policy 7:1, 243-274. [Abstract] [View PDF article] [PDF with links]

3. Gautam Gowrisankaran, Aviv Nevo, Robert Town. 2015. Mergers When Prices Are Negotiated: Evidence from the Hospital Industry. American Economic Review 105:1, 172-203. [Abstract] [View PDF article] [PDF with links]

4. Jason Allen, Robert Clark, Jean-François Houde. 2014. The Effect of Mergers in Search Markets: Evidence from the Canadian Mortgage Industry. American Economic Review 104:10, 3365-3396. [Abstract] [View PDF article] [PDF with links] 